\title{
Impact of network constraining on the terrestrial reference frame realization based on SLR observations to LAGEOS
}

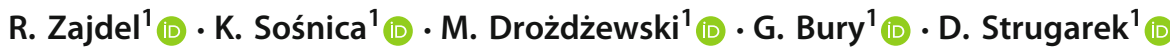

Received: 2 January 2019 / Accepted: 26 September 2019 / Published online: 17 October 2019

(c) The Author(s) 2019

\begin{abstract}
The Satellite Laser Ranging (SLR) network struggles with some major limitations including an inhomogeneous global station distribution and uneven performance of SLR sites. The International Laser Ranging Service (ILRS) prepares the time-variable list of the most well-performing stations denoted as 'core sites' and recommends using them for the terrestrial reference frame (TRF) datum realization in SLR processing. Here, we check how different approaches of the TRF datum realization using minimum constraint conditions (MCs) and the selection of datum-defining stations affect the estimated SLR station coordinates, the terrestrial scale, Earth rotation parameters (ERPs), and geocenter coordinates (GCC). The analyses are based on the processing of the SLR observations to LAGEOS-1/-2 collected between 2010 and 2018. We show that it is essential to reject outlying stations from the reference frame realization to maintain a high quality of SLR-based products. We test station selection criteria based on the Helmert transformation of the network w.r.t. the a priori SLRF2014 coordinates to reject misbehaving stations from the list of datum-defining stations. The $25 \mathrm{~mm}$ threshold is optimal to eliminate the epoch-wise temporal deviations and to provide a proper number of datum-defining stations. According to the station selection algorithm, we found that some of the stations that are not included in the list of ILRS core sites could be taken into account as potential core stations in the TRF datum realization. When using a robust station selection for the datum definition, we can improve the station coordinate repeatability by $8 \%, 4 \%$, and $6 \%$, for the North, East and Up components, respectively. The global distribution of datum-defining stations is also crucial for the estimation of ERPs and GCC. When excluding just two core stations from the SLR network, the amplitude of the annual signal in the GCC estimates is changed by up to $2.2 \mathrm{~mm}$, and the noise of the estimated pole coordinates is substantially increased.
\end{abstract}

Keywords Satellite Laser Ranging · Reference frame · Minimum constraints · Earth rotation parameters · Geocenter motion · Scale $\cdot$ LAGEOS $\cdot$ Helmert transformation

\section{Introduction}

The Satellite Laser Ranging (SLR) observations to LAGEOS-1 and LAGEOS-2 allow estimating precise positions and motions of SLR stations (Zelensky et al. 2014; Altamimi et al. 2016), tidal displacements (Bock et al. 2005; Sośnica et al. 2013; Bury et al. 2019b), Earth orientation parameters (EOPs) (Pavlis 1994; Glaser et al. 2015), the terrestrial scale (Bloßfeld et al. 2014), and time-variable Earth's gravity field (Bloßfeld et al. 2015; Sośnica et al. 2015). The SLR contribution to International Terrestrial Ref-

R. Zajdel

radoslaw.zajdel@upwr.edu.pl

1 Institute of Geodesy and Geoinformatics, Wrocław University of Environmental and Life Sciences, Grunwaldzka 53, 50-357 Wrocław, Poland erence Frame (ITRF) (Altamimi et al. 2016) is based on the observations to the two LAser GEOdynamics Satellites (LAGEOS) and two Etalons; however, the number of SLR observations to LAGEOS is more than ten times larger than those to Etalons (Appleby et al. 2016). Therefore, the relevance of Etalon-1/-2 data is thus marginal. The contribution of other geodetic satellites, such as Starlette, Stella, and Ajisai (Sośnica et al. 2014; Sośnica 2014; Bloßfeld et al. 2018), active low Earth-orbiting satellites (Arnold et al. 2018; Guo et al. 2018; Hellerschmied et al. 2018; Strugarek et al. 2019), as well as the constellation of Global Navigation Satellite Systems (GNSS) (Thaller et al. 2011; Zajdel et al. 2017; Sośnica et al. 2018, 2019) is still being investigated by many researchers. SLR integrates the three major pillars of the Global Geodetic Observing System (GGOS) (Plag and Pearlman 2009), i.e., the Earth gravity field, Earth rotation, and 
Earth geometry in one common adjustment (Bloßfeld et al. 2015). However, the quality of the SLR-based global geodetic parameters is uniquely associated with the network configuration, thus to the distribution of SLR observations, and the approach of the geodetic datum definition (Collilieux and Altamimi 2009; Otsubo et al. 2016).

In this paper, we analyze differences in station coordinates, the scale of the realized terrestrial reference frame (TRF), Earth rotation parameters (ERPs), and geocenter coordinates (GCC) derived from laser ranging observations to LAGEOS-1 and LAGEOS-2 (Pearlman et al. 2019), resulting from different strategies of TRF realization and datum site selection.

\subsection{SLR network status}

The spatial coverage of the stations is essential for the usefulness of the realized ITRF to the specific purposes in geoscience (Blewitt 2015). The geometry of the global SLR network is inhomogeneous (see Fig. 1) due to many economic and technical reasons. Over recent decades, the International Laser Ranging Service (ILRS) (Pearlman et al. 2002) community put a lot of effort in the expansion and development to fill up the gaps in the SLR network. In particular, the number of SLR sites has increased in the Russian territory and the southern hemisphere (Wilkinson et al. 2018). Nonetheless, the current network is concentrated mainly in Europe and East Asia, while the lack of stations is still clearly visible in the southern hemisphere (Kehm et al. 2018). Otsubo et al. (2016) showed that we should expect a significant improvement for the $\mathrm{X}$ and $\mathrm{Y}$ components of the geocenter and the sectorial gravity terms such as $C_{22}$ and $S_{22}$ by adding a station near the South Pole. Additionally, a station in middle latitudes would also significantly improve the tesseral gravity terms such as $C_{21}$ and $S_{21}$. Pavlis and Kuźmicz-Cieślak (2016) showed that the realization of the origin and scale of ITRF can be improved by approximately $50 \%$ when the number of well-distributed SLR core stations is increased from 8 to 32. Glaser et al. (2018) simulated local ties between different space geodetic techniques and concluded that excluding just one station, namely Hartebeesthoek, from the combination yields a bias of more than $0.8 \mathrm{~mm}$ in the TRF-defining parameters.

The second important limiting factor of the SLR network is the station-specific performance. The great majority of the SLR stations deliver a low number of observations when compared to the most effective stations. ${ }^{1}$ Only 12 out of 39 SLR stations exceeded the minimum number of 600 registered passes of LAGEOS satellites in 2017, which was requested by the ILRS Governing Board as the ILRS Pass

\footnotetext{
${ }^{1}$ https://ilrs.cddis.eosdis.nasa.gov/network/system_performance/ global_report_cards/index.html.
}

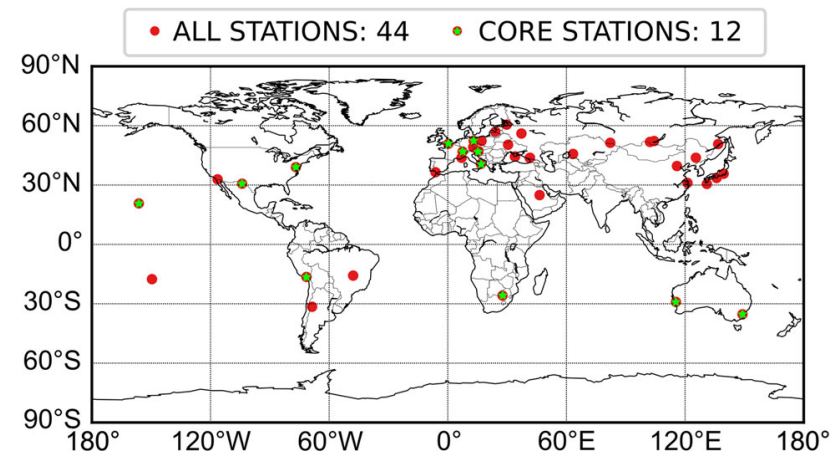

Fig. 1 Distribution of active SLR stations between 2010 and 2018

Performance Standard. Moreover, some stations do not meet the 5-mm short-term and 2-mm long-term bias stability of the ILRS data quality guidelines. The spatial distribution of high-quality SLR observations to LAGEOS satellites is oversampled above Europe and Australian regions. ${ }^{2}$ Even when a new well-performing station appears, some time is needed before precise reference coordinates can be assigned to this station allowing for participating in the TRF realization. These features are the major limiting factors in the datum realization of TRF in SLR global solution (Angermann and Müller 2009; Collilieux and Altamimi 2009; Kehm et al. 2018).

\subsection{Terrestrial reference frame realization}

The TRF may be realized in a global solution in one of the three ways (Weiss et al. 2017): (1) by imposing tight constraints on the positions of a particular set of stations in reference to the a priori values, (2) by estimating all station coordinates with loose constraints, or (3) by imposing minimum constraint conditions (MCs) on the network of stations (Kotsakis 2018). The ILRS operational products, which are delivered by the individual Analysis Centers (ACs), are loosely constrained to the a priori frame by imposing a loose $1 \mathrm{~m}$ constraints on all station coordinates and the equivalent of $1 \mathrm{~m}$ constraint for pole coordinates and LoD (Length-ofDay). ${ }^{3}$ However, the users who process the ILRS series most commonly use MC approach to realize the TRF in the SLR processing.

\subsubsection{Minimum constraint conditions}

The MCs are based on the 7-parameter similarity transformation originating from the Helmert transformation. Then, three groups of constraints can be imposed on the realized network

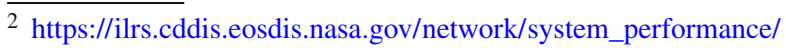
recent_groundtrack.html.

3 https://ilrs.cddis.eosdis.nasa.gov/docs/2007/

ILRS_products_070306.pdf.
} 


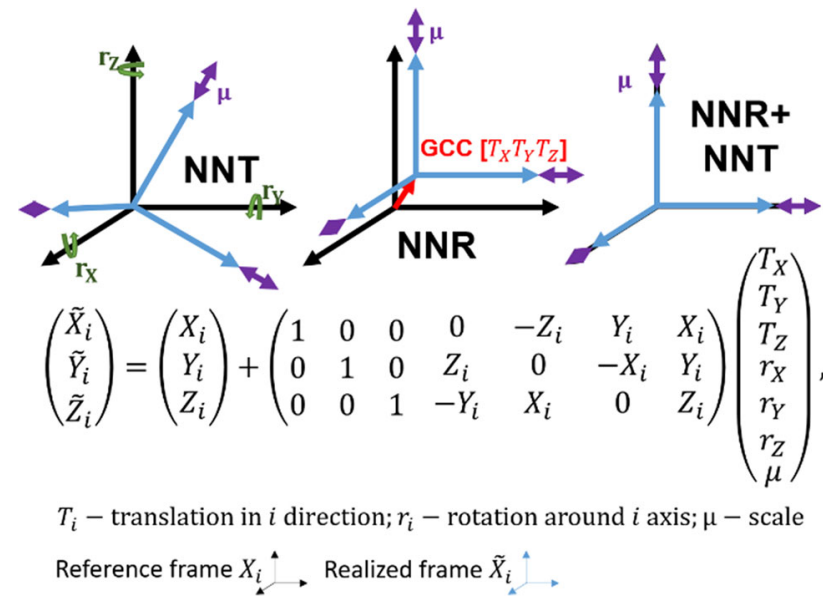

Fig. 2 Explanation of using minimum constraint conditions. $T_{i}$ translation in i direction; $r_{i}$-rotation around $i$ axis; $\mu$-scale; $X_{i}$ coordinates in the a priori reference frame; $\widetilde{X}_{i}$-coordinates in the realized frame

in reference to the a priori frame (Fig. 2): No-Net-Translation (NNT, three translation constraints), No-Net-Rotation (NNR, three rotation constraints) and No-Net-Scale (NNS, one scale constraint). In general, when station coordinates, EOPs, and orbits are estimated simultaneously in the processing, it is mandatory to apply NNR condition to remove singularities and invert the normal equation matrix (NEQ). The number of required constraints depends on the rank defect in the NEQ of the individual solution. The NNT condition is typically used for the datum definition of global networks with estimating GCC or in regional networks. The NNT condition manipulates the origin of the realized TRF.

\subsubsection{Origin of the terrestrial reference frame}

The origin of the realized TRF may be aligned to the Earth's Center-of-Mass (CoM) or Earth's Center-of-Figure ( $\mathrm{CoF})$. $\mathrm{CoM}$ is referred to the satellite dynamics since it points to the natural origin of the satellites' orbit. CoF is defined as a central point of the mathematical figure of the Earth. CoF could coincide with the barycentre of the infinitely dense network of points, which covers the solid Earth surface. Unfortunately, the Earth's figure is represented by a finite network of stations. Thus, it is to introduce a concept of Centerof-Network (CoN). According to Dong et al. (2003), the realization of the $\mathrm{CoF}$ is frankly impossible. In practice, the barycenter of the station network is directly dependent on the global station distribution. Thus, $\mathrm{CoN}$ is both variable in time and differs depending on the geodetic space technique used. The NNT condition ensures that the epoch-wise CoN of the realized TRF coincides with the $\mathrm{CoN}$ of the a priori TRF. Otherwise, the origin of the TRF, which is realized using satellite techniques, is theoretically CoM. Nonetheless, among the space techniques, only SLR observations to geodetic satellites allow us to realize the CoM frame. In principle, the CoM would be also available in GNSS and DORIS. However, due to the accumulated impact of technique-specific errors and model uncertainties both are able to access 'apparent CoM' rather than the true CoM (Bloßfeld et al. 2014; Zajdel et al. 2019; Rebischung and Garayt 2013).

\subsubsection{Selection of the datum-defining stations}

In principle, the MCs can be applied on any set of stations, however, an appropriate selection of datum-defining stations is crucial for the quality of the TRF realization, and hence the accuracy of the estimated parameters (Ray et al. 2017). Moreover, a global station coverage is essential for an appropriate TRF datum realization. The ILRS recommends using core stations ${ }^{4}$ to realize a TRF using MCs. The list of core stations is officially defined by the ILRS Analysis Standing Committee (ASC), considering the quality and stability of the entire set of network sites over several decades. The list of the ILRS core sites is time-variable and depends on the actual performance and reliability of the particular stations. However, using a constant "mean core network" can deteriorate the quality of the estimated frame, if, e.g., a datum station with temporally instable coordinates varies from its reference position (Blewitt 2015; Altamimi et al. 2016). Coulot et al. (2010) propose an external algorithm to dynamically choose the core sites in each 7-day SLR solution in order to optimize the estimation of ERPs in reference to the ITRF2005. Their results show an improvement of $10 \%$ of the stability for Polar Motion (PM) series in comparison with the results obtained with the network prepared by the ILRS ASC. Another approach to optimize the set of core stations in each 7-day solution is to verify the coordinates of the resulted TRF in reference to the a priori frame using a 7-parameter Helmert transformation. Thereby, the a priori frame, e.g., SLRF2014 is assumed to be error-free. The core sites with an RMS of residuals from the Helmert transformation, which exceed an assumed threshold, are rejected from the list of datum-defining stations. This approach is widely used by International GNSS Service (IGS) (Dow et al. 2009) ACs in the GNSS processing ${ }^{5}$ and some SLR studies (Angermann and Müller 2009; Sośnica 2014; Bloßfeld et al. 2015; Bury et al. 2019a; Drożdżewski and Sośnica 2018). However, the optimal threshold for station rejection is not yet established.

\footnotetext{
${ }^{4}$ https://ilrs.dgfi.tum.de/fileadmin/data_handling/

ILRS_Discontinuities_File.snx.

5 ftp://igs.org/pub/center/analysis/code.acn.
} 
Table 1 Description of the processing scheme and models

\begin{tabular}{ll}
\hline Type of model & Description \\
\hline Troposphere delay & Mendes-Pavlis delay model (Mendes and Pavlis 2004) \\
Cut-off angle & 3 deg, no elevation-dependent weighting \\
Satellite center of mass & Station- and satellite-specific (Appleby et al. 2012) \\
Length of arc & 7 days \\
Data editing & 2.5 sigma editing, maximum overall sigma: 25 mm, minimum 10 \\
& normal points per week \\
Relativity (orbit) & Schwarzschild, Lense-Thrirring, deSitter term, IERS 2010 (Petit and \\
& Luzum 2010) \\
Subdaily pole model & IERS Conventions 2010 (Petit and Luzum 2010) \\
Tidal forces & Solid Earth tide model, Pole tide model, Ocean pole tide model (Petit \\
& and Luzum 2010) \\
Loading corrections & Ocean tidal loading: FES2004 (Lyard et al. 2006) \\
Solar radiation pressure & Direct radiation applied with a fixed radiation pressure coefficient CR \\
& CR for LAGEOS-1 = 1.13; \\
& CR for LAGEOS-2 = 1.11; (Sośnica 2014; Hattori and Otsubo 2018) \\
Earth orientation parameters & IERS-14-C04 series (a priori), (Bizouard et al. 2018) \\
Reference frame & SLRF2014 realization of the ITRF2014 (Altamimi et al. 2016) \\
Earth gravity field & EGM2008 (Pavlis et al. 2012) \\
Ocean tide model & CSR4.0A (Eanes 2004) \\
\hline
\end{tabular}

\subsection{Goal of this paper}

In this paper, four main problems are taken into consideration:

- How do different minimum constraints in the datum realization affect the station coordinates?

- Is it better to determine SLR station coordinates in the CoF or CoM frame?

- Can we use 'non-CORE' stations to the datum realization and how does it affect the quality of station coordinates, terrestrial scale, GCC, and ERPs?

- What threshold should be taken when choosing datumdefining stations in the TRF datum realization?

Firstly, we compare the quality of station coordinates delivered in the particular solutions. Next, we evaluate the quality of GCC, ERPs and TRF scale estimates. Finally, the summary and conclusions of the results are provided.

\section{Methodology}

We prepared a standard 7-day LAGEOS-1/-2 solution based on observations delivered by the ILRS network throughout an 8-year interval between 2010 and 2018. In total, 418 weekly SLR solutions were generated. All computations, which are discussed in this paper, have been prepared using a mod- ified version of the Bernese GNSS Software (Dach et al. 2015) dedicated to the processing of optical observations. The solutions follow most of the standards of the ILRS ASC solutions used for the operational products. Details of the processing scheme are summarized in Table 1. Nonetheless, there are some differences in the methodology compared to the standard ILRS solutions, which are routinely prepared by the ILRS ACs.

Firstly, a piecewise linear (PWL) parametrization for the ERPs is applied, instead of piecewise constant (PWC) as for the standard ILRS solution. Thaller et al. (2010) indicated that such kind of a parametrization is beneficial for the estimation of ERPs in SLR solution. The main disadvantage of PWC parameterization is that the resulting time series of ERPs have discontinuities at the day boundaries, whereas the orbit is parameterized as a continuous arc over the entire week. In PWL parametrization of the ERPs, all the parameters are continuous throughout the 7-day solution. Moreover, one UT1-UTC value is constrained to the a priori value at the midnight between the third and fourth day of the arc.

In the case of datum definition, we tested different combinations of using NNR and NNT constraints on the selected group of datum-defining stations, instead of $1 \mathrm{~m}$ loose constraints (described in Sect. 2.1). Such an approach is parallel to the one used in the ILRS combined product. The following parameters have been estimated: SLR station coordinates, LAGEOS orbit parameters, X and Y pole coordinates, UT1 - UTC, geocenter coordinates and range biases for selected stations (according to the recommendations of the ILRS Data 
Table 2 Description of the estimated parameters

\begin{tabular}{ll}
\hline Estimated parameters & Description \\
\hline Satellite orbits & One set per 7-day arc 6 \\
& Keplerian elements, 5 \\
& empirical parameters: A \\
& constant along-track \\
& acceleration, \\
& once-per-revolution \\
& parameters in along-track \\
& and cross-track \\
One set per 7-day arc, X, Y, & Z components for every \\
station \\
One set per 7-day arc. \\
Estimated only for \\
selected SLR stations \\
according to the ILRS \\
Data Handling File \\
8 parameters per 7-day arc \\
using PWL \\
parameterization. Pole X \\
and Y coordinates and \\
UT1-UTC with one \\
parameter fixed to the a \\
priori IERS-14-C04 series \\
One set per 7-day arc \\
Estimated in selected \\
solutions, see Table 3 \\
\hline
\end{tabular}

Handling File approved by the ILRS ASC). All parameters are estimated with the 7-day interval, except for the ERPs, which are calculated with a daily resolution (see Table 2).

\subsection{Solutions}

The analyzed solutions differ mainly in three aspects (Table 3): (1) the approach for the TRF datum realization, (2) the group of stations, which are considered to be used in the TRF datum realization, (3) the threshold for the Helmert transformation to accept the particular stations in the TRF datum realization.

Weekly TRF solutions are carried out using the two LAGEOS satellites alone. The NEQ has three singularities corresponding to the $3 \mathrm{D}$ rotation of the whole frame resulting from the simultaneous estimation of station coordinates, ERPs and orbits. In the solutions named 'NG', only NNR are imposed on the network, which is sufficient to remove singularities and invert the NEQ. Because only the NNR are applied, the origin of the realized TRF is CoM, as transferred from the LAGEOS orbit dynamics. This is unique when compared to the TRF derived from, e.g., GNSS and DORIS, for which the connection to CoM is not as strong as when using direct laser range observations. Therefore, we may say that the TRF in the SLR solutions, which are named 'NG', are purely geocentric. The solutions named ' $G$ ' imply that the geocenter vector is estimated as a parameter in the processing. When estimating GCC, the NEQ gains three additional singularities corresponding to the translation of the whole frame. Therefore, we have to impose the minimum NNT constraint on the network. The origin of the estimated station coordinates should then be consistent with the origin of the a priori TRF by definition. The geocenter motion is thus estimated in the 'network shift approach' (Blewitt et al. 1992; Wu et al. 2012). When simultaneously estimating GCC and imposing NNT, the estimated station coordinates are given in the $\mathrm{CoN}$ frame which should be close to the $\mathrm{CoF}$ in case of a well-distributed network of stations. The 'NG' solutions are purely minimal constraint solutions. On the other hand, the ' $G$ ' solutions are derived from expanding the NEQ in terms of estimating the GCC. The NNT is practically 'artificial minimum constraint' as it is required only to retrieve the geocenter motion in the network shift approach. Finally, in the 'O' solution both NNR and NNT conditions are applied; however, the GCC is not estimated as additional parameters, which results in a pure over-constrained solution. In such an approach, the NNT condition cannot be treated as a minimal constraint. Moreover, the geocenter motion is not handled. Therefore, all parameters, which are estimated in the processing, are affected by the realization approach of the SLR origin, especially ERPs, satellite orbits, and station coordinates. The solution is also affected by the correlations between rotations and translations of the network, especially for the inhomogeneously distributed, sparse global networks (Bloßfeld et al. 2014).

We tested two groups of solutions with a different list of 'station candidates' for the datum realization. In the 'CORE' group, we consider only stations, which were indicated by the ILRS ASC as core sites in the considered period. According to the ILRS recommendations, Changchun (7237) was considered as a core site $^{6}$ for operational solutions but not for the TRF development. Therefore, we excluded Changchun from the 'CORE' group in this study. In the 'ALL' group, all the stations which were involved in the particular 7-day solutions were initially allowed for the TRF datum realization.

The MCs should be imposed on a selected group of the most stable stations only. Therefore, the process of the parameter estimation is performed in two independent iterations. Firstly, we estimate all the parameters, while the MCs are applied to the entire group of datum-defining 'station candidates'. After the first iteration, the resulted station coordinates are iteratively checked using the 7-parameter similarity transformation in reference to the a priori SLRF2014 coordinates. The 'station candidates' are removed one by one, until all the residuals for all stations and all station components

\footnotetext{
6 https://ilrs.dgfi.tum.de/fileadmin/data_handling/ ILRS_Discontinuities_File.snx.
} 
Table 3 Description of the solutions

Realization of the terrestrial reference frame

\begin{tabular}{llll}
\hline Solution name & Estimation of GCC & NNR & NNT \\
\hline 'NG' No Geocenter & NO & YES & NO \\
'G' Geocenter & YES & YES & YES \\
'O' Over-constrained & NO & YES & YES
\end{tabular}

List of 'stations candidates'

\begin{tabular}{ll}
\hline Station name & Description \\
\hline CORE & $\begin{array}{l}\text { Only CORE stations are used for the TRF } \\
\text { datum realization } \\
\text { ALL }\end{array}$ \\
$\begin{array}{l}\text { All stations allowed for the TRF datum } \\
\text { realization }\end{array}$ \\
\hline
\end{tabular}

Thresholds used for station-outlier rejection in the Helmert Transformation

Station name Thresholds used for station-outlier rejection in the Helmert Transformation

\begin{tabular}{|c|c|}
\hline $\mathrm{HN}$ & $\begin{array}{l}\text { Helmert Transformation with thresholds for } \\
\text { components: North: } \mathrm{N} \text { mm, East: } \mathrm{N} \text { mm, Up: } \mathrm{N} \text { mm }\end{array}$ \\
\hline $\mathrm{NH}$ & No outlier rejection \\
\hline
\end{tabular}

are below the selected threshold. Only stations which pass this multi-step outlier rejection procedure are considered as datum-defining in the final parameter estimation. We tested six gradually rising station rejection thresholds of 10,15 , $25,35,45,55 \mathrm{~mm}$, to choose the best set of datum-defining stations and find the optimal processing strategy. The subsequent thresholds refer to the names of the corresponding solutions, which are H10, H15, H25, H35, H45, and H55, respectively. Finally, the solutions named 'NH' assume that no stations are rejected after the first iteration. Table 3 provides the explanation of the acronyms and a short description of each solution.

\subsection{Station efficiency}

\subsubsection{Collected dataset}

First, we analyzed the number of normal points, which were delivered by the SLR stations in the considered period. Figure 3 shows the number of normal points collected by the SLR stations after the residual screening. In total, 638,026 normal points to LAGEOS- 1 and 567,401 to LAGEOS-2 were taken into account. The mean number of observations to LAGEOS2 is at a comparable level to the number of observations to LAGEOS-1, i.e., on average 3000 normal points available in each weekly solution. However, more observations were gathered in the period 2011-2013, than in successive years. This fact is caused by the continuously increasing list of the satellite targets which are supported by the ILRS and recent

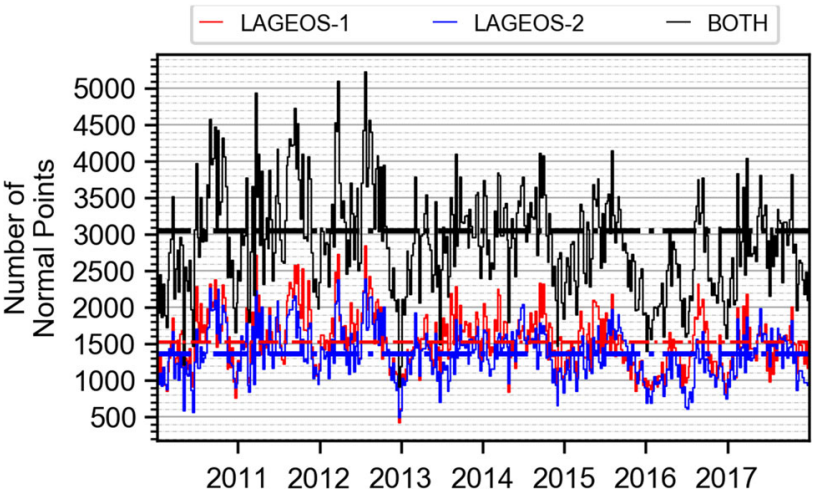

Fig. 3 Time series of the normal point observations to the both LAGEOS satellites from 7-day solutions. Horizontal lines indicate mean number of observations for the particular time series

tracking outages of some stations, such as San Juan (7406), Concepcion (7405), and McDonald (7080).

The productivity of the ILRS network depends on many factors. The stations have different cloud cover conditions due to the varied geographical locations. Moreover, stations operate at different levels of technology and operational regimes. Figure 4 illustrates the number of normal points delivered by the particular stations in the subsequent years. In 2015 the Governing Board set a new ILRS Pass Performance Standard to 3500 passes per year. ${ }^{7}$ In terms of LAGEOS, the stations should collect four passes per week to each LAGEOS satellite which gives 600 LAGEOS passes per year. Almost $16 \%$ of the observations in the analysis are delivered by the Yarragadee station (7090), while the second most effective station Zimmerwald (7810) deliver 9\% of all observations. Some of the stations started to deliver more observations during the period of the analysis, for instance, new Wettzell Satellite Observing System (SOS-W; 7827) and Changchun (7237). On the other hand, some of the stations decreased their efficiency in time, such as Wettzell Laser Ranging System (WLRS; 8834) and McDonald (7080) or have been closed, such as Concepcion (7405), San Fernando (7824) or Riyadh (7832).

\subsubsection{Station suitability for the TRF datum realization}

We analyze two groups of 'station candidates' as well as six thresholds for outlying stations detection (see Table 3). Both aspects manipulate the distribution and the number of datum-defining stations. When using a different group of datum-defining stations, one should expect differences in terms of the shift of the network barycenter (i.e., $\mathrm{CoN}$ ) in reference to the a priori TRF origin. This change has a direct impact on the quality of the estimated global geode-

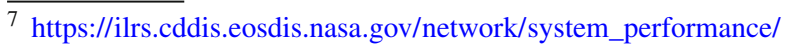
index.html.
} 
Fig. 4 Number of normal points to both LAGEOS satellites collected by the particular stations in the subsequent years. The values are given in thousand normal points. The "C_," prefix denotes core sites based on the ILRS recommendations
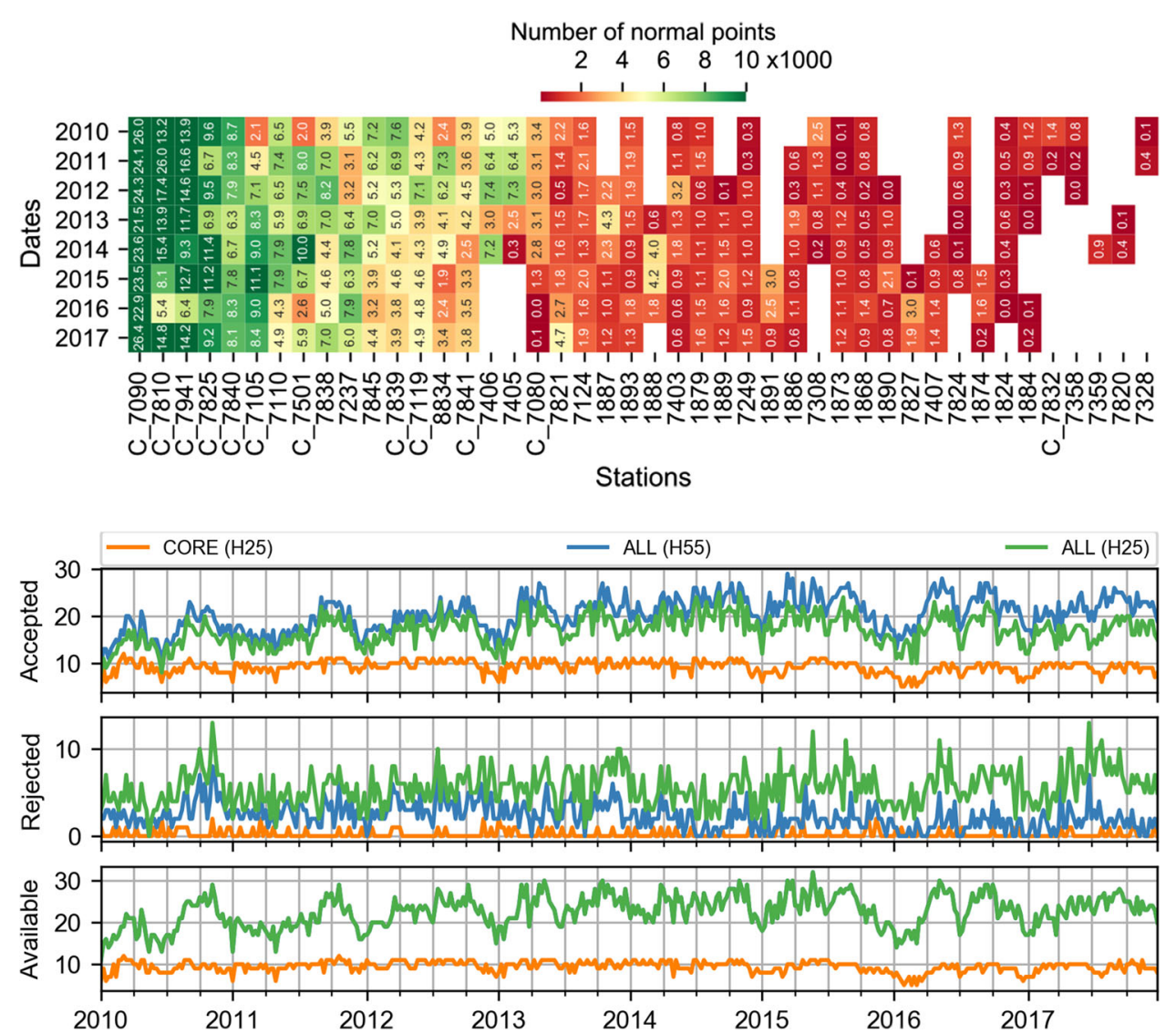

Fig. 5 Number of datum-defining stations which participated in the reference frame datum realization for the particular solutions. The top panel illustrates the number of accepted stations from the list of 'station candidates'. The middle panel illustrates the corresponding number of rejected stations. The bottom panel illustrates the total number of 'station candidates' in particular solutions tic parameters. Figure 5 illustrates the number of stations which participated in the TRF datum realization in each 7-day solution. From 41 stations, which observed LAGEOS-1/-2 in the analyzed period, only 12 were considered by the ILRS as 'core' SLR sites. However, the median number of core sites which were available for the solution is only 9. On the other hand, the number of stations, which deliver observations in particular 7-day solutions, does not exceed 30, while the median is at the level of 23 stations. We tried to see whether any stations outside the list of core sites are suitable for the datum definition. Table 4 shows the median number of accepted stations for the TRF datum realization in particular solutions. We can even double the number of accepted stations when 'ALL' available stations are considered for the TRF datum realization. Even when the very rigorous threshold is applied, e.g., ALL (H15), the median number of accepted stations is increased only by 2 stations with respect to CORE (H15) solution (see Table 4).

Figure 6 shows the percentage of the epochs when particular stations have been accepted to participate in the datum realization in reference to their overall efficiency. In the group of CORE solutions, we see that there is only a limited number of epochs when particular core stations were rejected from the TRF datum realization. These stations were accepted even when $10 \mathrm{~mm}$ threshold is applied, hence proves that they are
Table 4 Statistics of the number of stations which participated in the reference frame datum realization for the particular solutions

\begin{tabular}{lllllll}
\hline Solution & & \multicolumn{2}{c}{ Accepted } & & Rejected & \\
& & Median & Std & & Median & Std \\
\hline CORE-NG & $(\mathrm{H} 55)$ & 9 & 1 & 0 & 0 \\
CORE-NG & $(\mathrm{H} 45)$ & 9 & 1 & 0 & 0 \\
CORE-NG & $(\mathrm{H} 35)$ & 9 & 1 & 0 & 0 \\
CORE-NG & $(\mathrm{H} 25)$ & 9 & 1 & 0 & 0 \\
CORE-NG & $(\mathrm{H} 15)$ & 9 & 1 & 1 & 1 \\
CORE-NG & $(\mathrm{H} 10)$ & 8 & 1 & 2 & 1 \\
ALL-NG & $(\mathrm{H} 55)$ & 20 & 4 & 2 & 2 \\
ALL-NG & $(\mathrm{H} 45)$ & 20 & 4 & 3 & 2 \\
ALL-NG & $(\mathrm{H} 35)$ & 19 & 3 & 4 & 2 \\
ALL-NG & $(\mathrm{H} 25)$ & 17 & 3 & 6 & 2 \\
ALL-NG & $(\mathrm{H} 15)$ & 13 & 3 & 9 & 3 \\
ALL-NG & $(\mathrm{H} 10)$ & 11 & 2 & 12 & 3 \\
\hline
\end{tabular}

very stable in time and correctly assigned by the ILRS. For 'ALL' solutions, some stations outside the list of core sites were accepted when using the proposed criteria. The most frequently accepted stations outside the core list are: 7110 (Monument Peak, USA), 7237 (Changchun, China), 8834 (Wettzell, Germany), 7845 (Grasse, France), 7124 (Tahiti, 


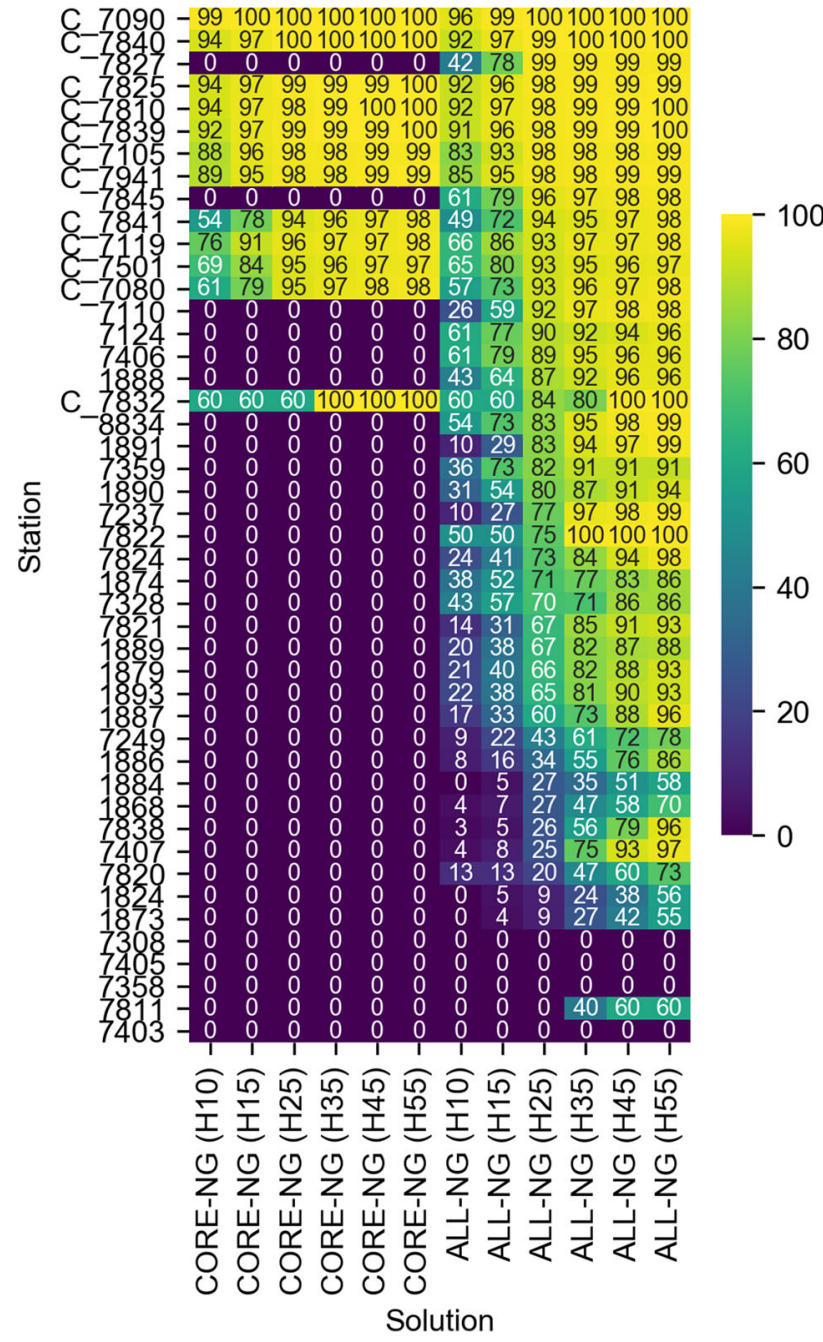

Fig. 6 Percentage of the epochs when particular stations were accepted for the datum definition to their overall efficiency. Stations are sorted by descending percentages in ALL-NG (H25) solution. The " $\mathrm{C}_{-}$" prefix denotes core sites based on the ILRS recommendations

French Polynesia), 7406 (San Juan, Argentina), 1888 (Svetloe, Russia), 1890 (Badary, Russia) and 7827 (Wettzell, Germany). The vast majority of them were accepted for the datum realization in $80-90 \%$ of their occurrences when the threshold of $25 \mathrm{~mm}$ was applied.

Observations delivered by Changchun (7237) are biased because of inferior a priori station coordinates and several device issues at the station (Zajdel et al. 2017; Sośnica et al. 2019). Thus, it is regularly rejected and its positive impact on the TRF datum realization is questionable despite high productivity. The same applies to most of the Russian stations ('18' prefix in station numeration), which were not considered in the ITRF2014 realization or contributed with a very short observation period. The Wettzell WLRS station (8834) is rejected from the list of core sites since the middle of 2009, even though it was accepted for the TRF datum realization in most cases (see Figs. 6, 7). The Wettzell SOS-W station (7827) also has been performing very well since 2016, with the $99 \%$ of accepted occurrences in the ALL (H25) solution. The stations 7403 (Arequipa, Peru), 7405 (Concepcion, Chile, inactive since 2014), 7308 (Koganei, Japan) and 7358 (Tanegashima, Japan) have never been accepted for datum realization, which is caused by the issues in the a priori station coordinates including nonlinear postseismic deformations, ${ }^{8}$ inferior quality of the observations or the necessity of solving for range biases which affects the estimated station coordinates, i.e., 7403 (Arequipa, Peru) and 7308 (Koganei, Japan). Apart from the very good performance of McDonald (7080) (see Fig. 6), it stopped delivering a large number of observations after the telescope change in August 2015. Since then, McDonald has not been accepted for TRF datum realization any more (Fig. 7).

\section{Results}

\subsection{Station coordinates}

We examine the differences in the quality of station coordinates delivered from the particular solutions using coordinate repeatability as the quality indicator. Three main aspects directly connected with the TRF datum realization are analyzed: (1) the impact of using a different set of MCs, (2) the impact of using a different set of 'station candidates' for TRF datum realization and (3) the impact of using a different thresholds for the selection of datum-defining stations.

\subsubsection{Impact of the TRF datum realization approach on the station coordinates}

First, we tested the differences between the solutions which employ only the NNR constraint (solutions 'NG') compared to the solutions which employ both NNR and NNT constraints (solutions ' $G$ ' and 'O', see Table 3). Station coordinates in the solutions ' $N G$ ' are shifted w.r.t. solutions ' $G$ ' by the GCC as seen by SLR. The additional NNT constraint imposed on the network makes the estimated station coordinates consistent in origin with the a priori TRF. We should then expect the decrease in the SCR when using NNT because no geocenter motion is included in the signal of station coordinate time series (see Fig. 8a) as opposed to the ' $\mathrm{NG}$ ' where the station coordinates include the geocenter signal and purely reflects a CoM frame. Figure 8c shows also the difference between the CORE-G (H25) and CORE$\mathrm{O}$ (H25). In both solutions, the same set of MCs is applied to the network; however, the GCC is estimated as additional parameters only in the solution ' $G$ '. As we see, both solutions

\footnotetext{
8 ftp://itrf.ign.fr/pub/itrf/itrf2014/ITRF2014-psd-slr.dat.
} 
Fig. 7 Suitability of the particular stations for the TRF datum realization in each weekly solution based on the solution ALL (H25). Blue color indicates that the station was accepted, while red color indicates that the station was rejected from the TRF datum realization. Stations are sorted with the same regime as for Fig. 6. The "C_" prefix denotes core sites based on the ILRS recommendations

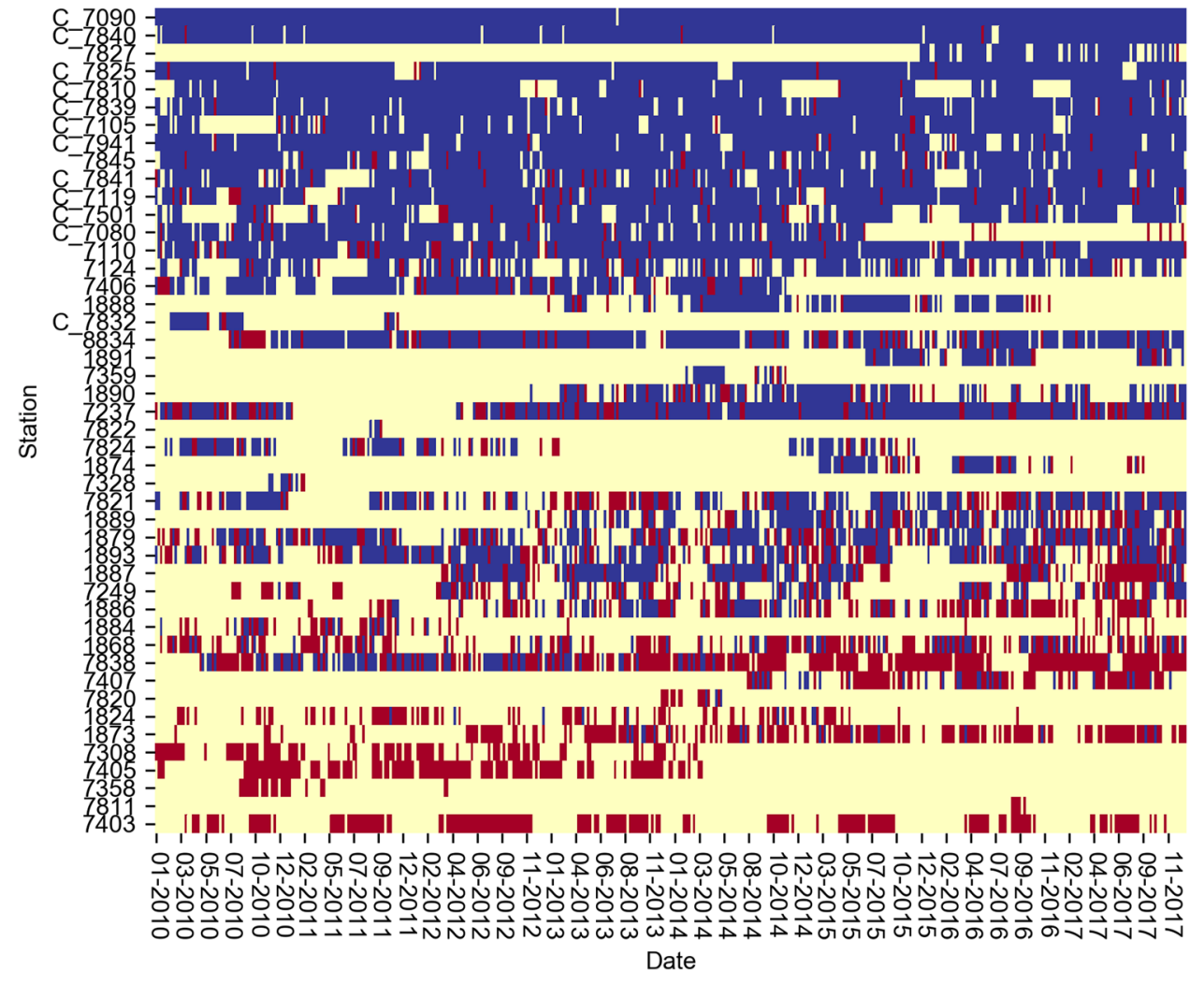

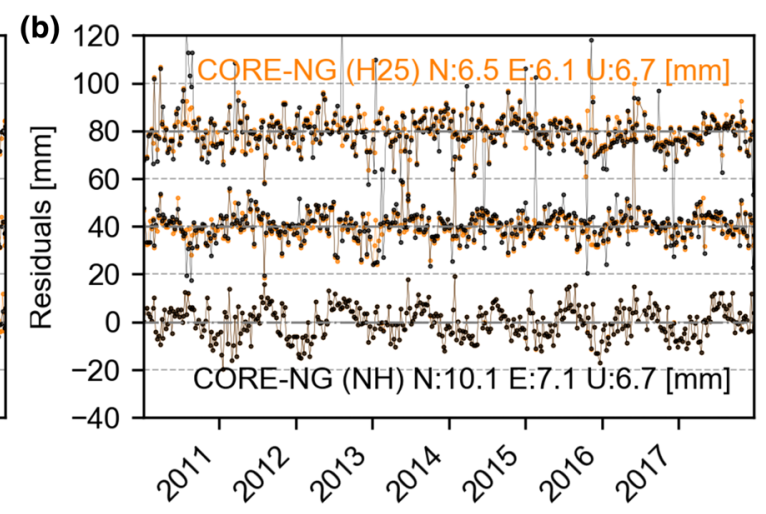
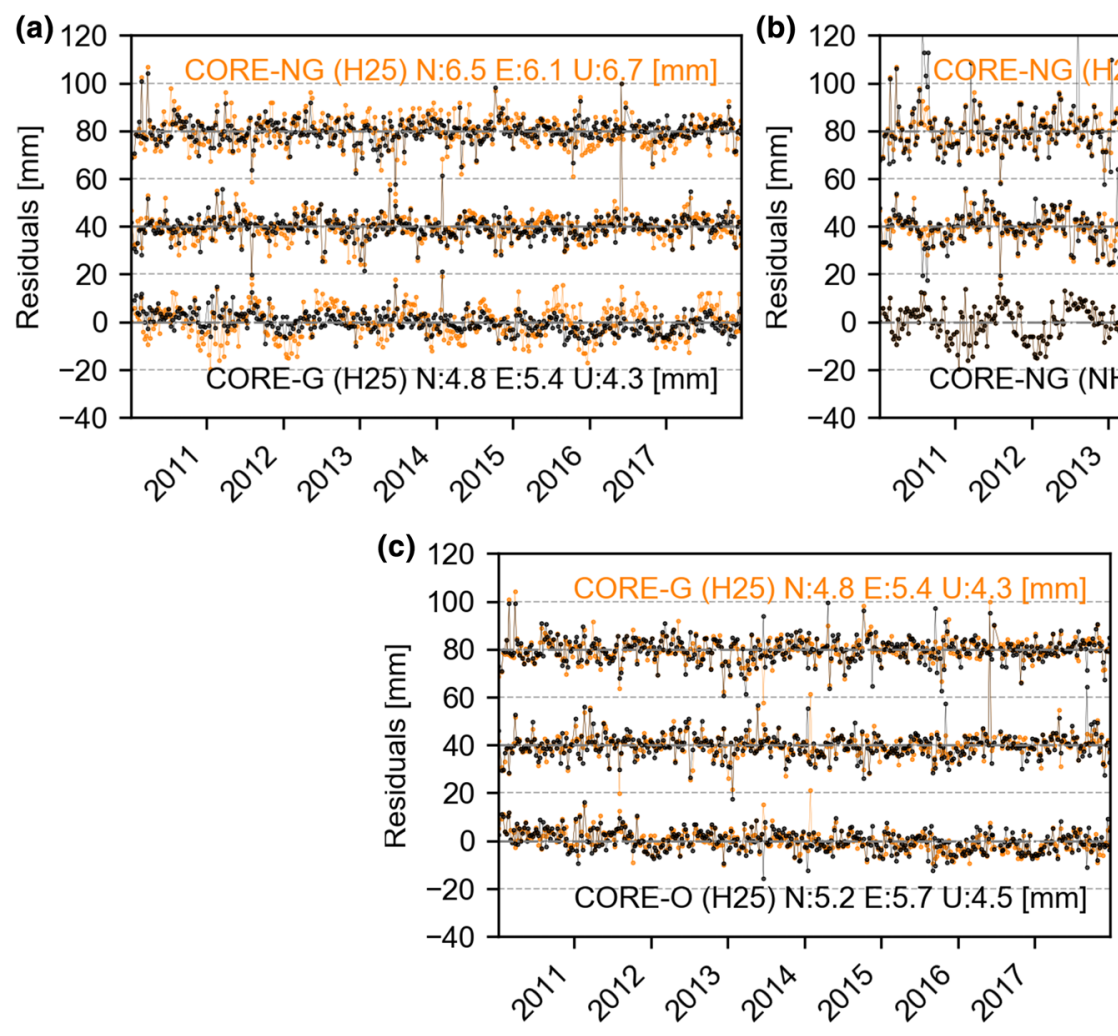

Fig. 8 The time series of the station coordinate residuals w.r.t. the a priori SLRF2014 for the station 7840 (Herstmonceaux) in the particular solutions. The station coordinates are decomposed into the North (top), East (middle), Up (bottom) components. The components are shifted on the $\mathrm{y}$-axis by $40 \mathrm{~mm}$. a Comparison between CORE-NG (H25) and CORE-G (H25) solutions. b Comparison between CORE-NG (NH) and CORE-NG (H25) solutions. c Comparison between CORE-G (H25) and CORE-O (H25) solutions 
Fig. 9 Coordinate repeatability for twenty best-performing stations in selected solutions, decomposed into the North, East and, Up components. The color bars without edges represent the 'NG' solution (NNR-only; GCC not estimated), while the shadow bar with edges represents the corresponding ' $\mathrm{G}$ ' solution (NNR+NNT; GCC estimated). The "C_" prefix denotes core sites based on the ILRS recommendations

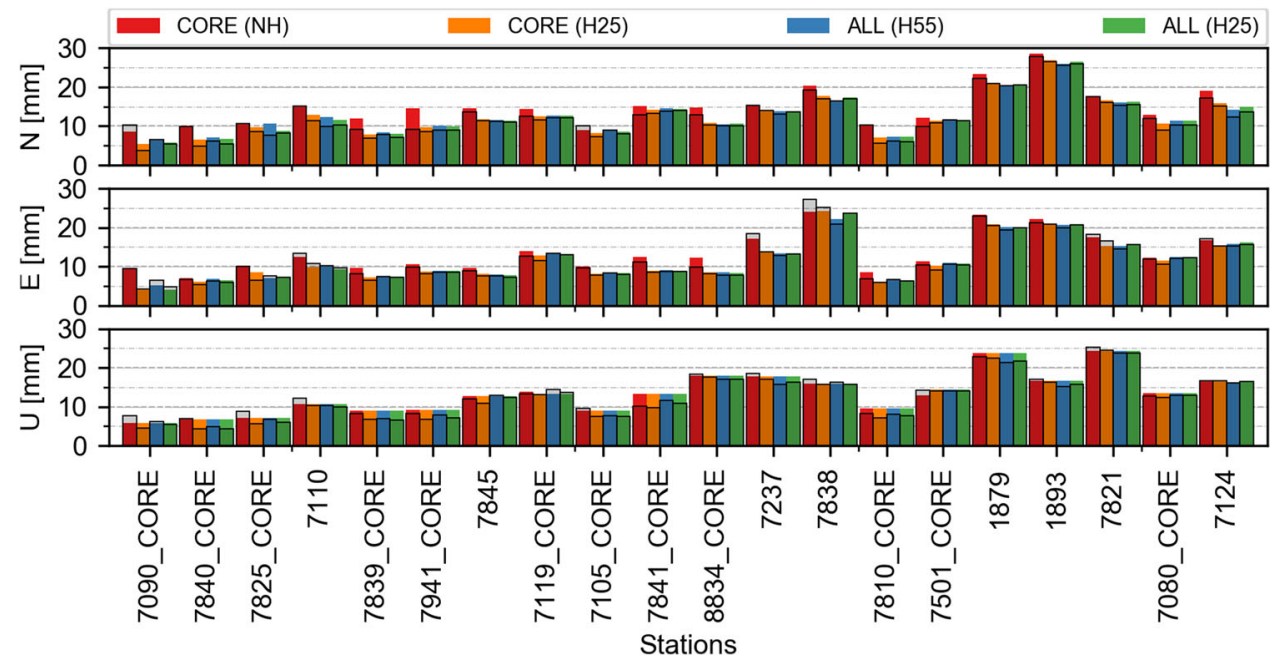

roughly correspond to each other. However, the SCR is worse at the sub-millimeter level in CORE-O (H25) when compared to CORE-G (H25). If we over-constrain the solution and do not estimate the GCC as a parameter, we influence the estimated station coordinates. The translation of the origin of the CORE-O (H25) w.r.t the CORE-G (H25) remains well below $1 \mathrm{~mm}$. However, the RMS of the similarity transformation is at the level of $4.0 \pm 2.8 \mathrm{~mm}$.

Now, we discuss the differences between the solutions 'NG' and 'G'. Figure 9 shows the station coordinate repeatability (SCR) of 20 most effective SLR sites, decomposed into the North, East and Up components for particular solutions. Figure 10 shows the aggregated statistics of SCR for the selected solutions, while the numerical data for Fig. 10 are summarized in Table 5.

In general, the median decrease of SCR when compared CORE-G (H25) with CORE-NG (H25) is at the level of $3 \%, 1 \%$ and 5\% for the North, East and Up components, respectively (see Fig. 9). On the other hand, the decrease of SCR is slightly better when compared ALL-G (H25) with ALL-NG (H25) and equals 4\%,1\% and 6\% for the North, East and Up components. The improvement of SCR is considerably larger for the SLR stations which participated in the TRF datum realization. If we limit the consideration to the ILRS core sites only, the decrease of SCR is at the level of $11 \%, 8 \%$, and $21 \%$, for the North, East and Up components, respectively, when comparing COREG (H25) with CORE-NG (H25). In the case of the 'ALL' solutions, the particular stations were occasionally accepted for TRF datum realization, e.g., 7110 or 7237 . Thus, the reduction of SCR between ALL-G (H25) and ALL-NG (H25) is more spread over all the stations. The reduction of SCR for the ILRS core sites is lower than for the 'CORE' solution and remains at the level of $7 \%, 2 \%$, and $16 \%$, for the North, East and Up component, respectively. In summary, when we use more stations for the TRF datum realization,
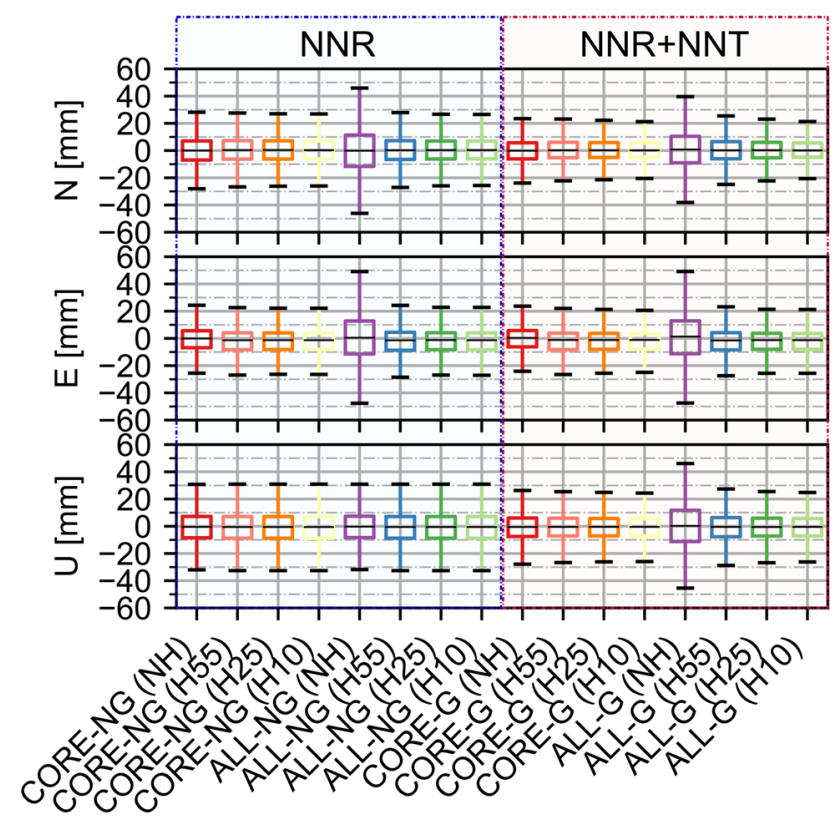

\section{Solutions}

Fig. 10 Boxplots of the summarized station coordinate repeatabilities for the particular solutions, decomposed into North (N), East (E) and Up (U) components

the reduction of SCR is lower but for the wider group of stations. Moreover, the greatest decrease is visible for the Up component compared to the North and East components.

However, there are no differences in the repeatability of the 'Up' coordinate components between the particular solutions, when only the NNR constraints are imposed on the network (see Fig. 9 and Table 5). The 'NG' solutions differ only in the set of datum-defining stations. The whole network is only rotated, but neither rescaled nor translated. Therefore, it is naturally expected that the change in a set of stations used 
Table 5 Numerical statistics of the summarized station coordinate repeatabilities for the particular solutions, decomposed into the North, East, and Up components

\begin{tabular}{|c|c|c|c|c|c|c|c|c|}
\hline \multirow[t]{2}{*}{ Solution } & & \multicolumn{2}{|c|}{ North [mm] } & \multicolumn{2}{|c|}{ East (mm) } & \multicolumn{2}{|c|}{$\mathrm{Up}(\mathrm{mm})$} & \multirow[t]{2}{*}{ STA } \\
\hline & & Median & IQR & Median & IQR & Median & IQR & \\
\hline CORE-NG & $(\mathrm{NH})$ & 0.0 & 14.1 & 0.0 & 12.5 & -0.5 & 15.7 & 9 \\
\hline CORE-NG & (H55) & 0.4 & 13.6 & -1.4 & 12.4 & -0.6 & 15.9 & 9 \\
\hline CORE-NG & (H45) & 0.4 & 13.5 & -1.3 & 12.3 & -0.6 & 15.9 & 9 \\
\hline CORE-NG & (H35) & 0.4 & 13.5 & -1.3 & 12.3 & -0.6 & 15.9 & 9 \\
\hline CORE-NG & (H25) & 0.4 & 13.4 & -1.3 & 12.2 & -0.6 & 15.9 & 9 \\
\hline CORE-NG & (H15) & 0.3 & 13.2 & -1.3 & 12.2 & -0.6 & 15.9 & 9 \\
\hline CORE-NG & (H10) & 0.3 & 13.2 & -1.3 & 12.2 & -0.6 & 15.9 & 8 \\
\hline ALL-NG & $(\mathrm{NH})$ & -0.1 & 23.0 & 0.5 & 24.2 & -0.3 & 15.7 & 22 \\
\hline ALL-NG & (H55) & 0.3 & 13.8 & -1.4 & 13.2 & -0.6 & 15.9 & 20 \\
\hline ALL-NG & (H45) & 0.2 & 13.6 & -1.2 & 13.1 & -0.6 & 15.9 & 20 \\
\hline ALL-NG & (H35) & 0.2 & 13.5 & -1.3 & 12.9 & -0.6 & 15.9 & 19 \\
\hline ALL-NG & $(\mathrm{H} 25)$ & 0.4 & 13.2 & -1.2 & 12.5 & -0.6 & 15.9 & 17 \\
\hline ALL-NG & (H15) & 0.3 & 12.9 & -1.2 & 12.4 & -0.6 & 15.9 & 13 \\
\hline ALL-NG & (H10) & 0.4 & 13.1 & -1.3 & 12.5 & -0.6 & 15.9 & 11 \\
\hline CORE-G & $(\mathrm{NH})$ & -0.1 & 11.8 & 0.4 & 12.2 & -0.6 & 13.6 & 9 \\
\hline CORE-G & (H55) & 0.2 & 11.4 & -1.2 & 12.0 & -0.5 & 13.0 & 9 \\
\hline CORE-G & (H45) & 0.2 & 11.2 & -1.1 & 12.0 & -0.5 & 13.0 & 9 \\
\hline CORE-G & (H35) & 0.2 & 11.2 & -1.1 & 11.9 & -0.5 & 12.9 & 9 \\
\hline CORE-G & (H25) & 0.2 & 10.9 & -1.2 & 11.7 & -0.4 & 12.8 & 9 \\
\hline CORE-G & (H15) & 0.2 & 10.6 & -1.1 & 11.6 & -0.5 & 12.7 & 9 \\
\hline CORE-G & (H10) & 0.1 & 10.4 & -1.1 & 11.4 & -0.4 & 12.6 & 8 \\
\hline ALL-G & $(\mathrm{NH})$ & 0.8 & 19.5 & 1.4 & 24.2 & 0.3 & 23.0 & 22 \\
\hline ALL-G & (H55) & 0.2 & 12.6 & -1.5 & 12.7 & -0.5 & 14.1 & 20 \\
\hline ALL-G & (H45) & 0.2 & 12.2 & -1.2 & 12.2 & -0.6 & 13.7 & 20 \\
\hline ALL-G & (H35) & 0.2 & 12.0 & -1.5 & 12.2 & -0.5 & 13.5 & 19 \\
\hline ALL-G & $(\mathrm{H} 25)$ & 0.3 & 11.4 & -1.3 & 11.8 & -0.6 & 13.1 & 17 \\
\hline ALL-G & (H15) & 0.1 & 10.9 & -1.2 & 11.8 & -0.5 & 13.0 & 13 \\
\hline ALL-G & (H10) & 0.1 & 10.5 & -1.3 & 11.7 & -0.5 & 12.8 & 11 \\
\hline
\end{tabular}

STA denotes the median number of stations accepted for the reference frame realization; IQR denotes the inter-quartile range for NNR constraints has no impact on the station heights in NNR-only solutions.

\subsubsection{Impact of the threshold on the station coordinates}

For each solution, we checked what is the impact on SCR when changing the threshold for the selection of datumdefining stations. The improvement is significant between solutions without station rejection 'NH' and other solutions which apply a threshold for outlying station rejection. When using the robust station selection for the datum definition, i.e., solution CORE-G (H25), we improve the SCR by $8 \%$, $4 \%$, and $6 \%$, for North, East and Up coordinates, respectively, when compared to the CORE-G (NH) solution. That clearly emphasizes that the list of datum-defining stations has to be filtered from the epoch-wise blunders, which spoil the quality of the certain 7-day solutions. Figure 8b shows the repeatability of the coordinates which is almost the same between the solutions ' $\mathrm{NH}$ ' and ' $\mathrm{H} 25$ ', apart from the single epochs where an outlying station has probably participated in the TRF datum realization. This is particularly important for the group of 'ALL' solutions which permits more unreliable stations for the TRF datum realization. The gradual improvement is visible when the threshold is getting smaller. By the example of the CORE-G (H55) in reference to the CORE$\mathrm{G}$ (H10) solution, the inter-quartile range (IQR) of the SCR changes from 11.4 to $10.4 \mathrm{~mm}$, from 12.2 to $11.4 \mathrm{~mm}$, and from 13.0 to $12.6 \mathrm{~mm}$ for the North, East, and Up components, respectively. 
Fig. 11 Residuals of the coordinate differences in reference to the a priori values from SLRF2014 as the function of the number of observations delivered by the particular station in the weekly solutions. Blue dots denote individual solutions, whereas a black line denotes a median value

Fig. 12 Characteristics of the geocenter coordinates, estimated in the particular solutions. Left: the time series of geocenter coordinates. A 63-day mean is fitted to individual solutions. Right: spectral analysis of the geocenter coordinates
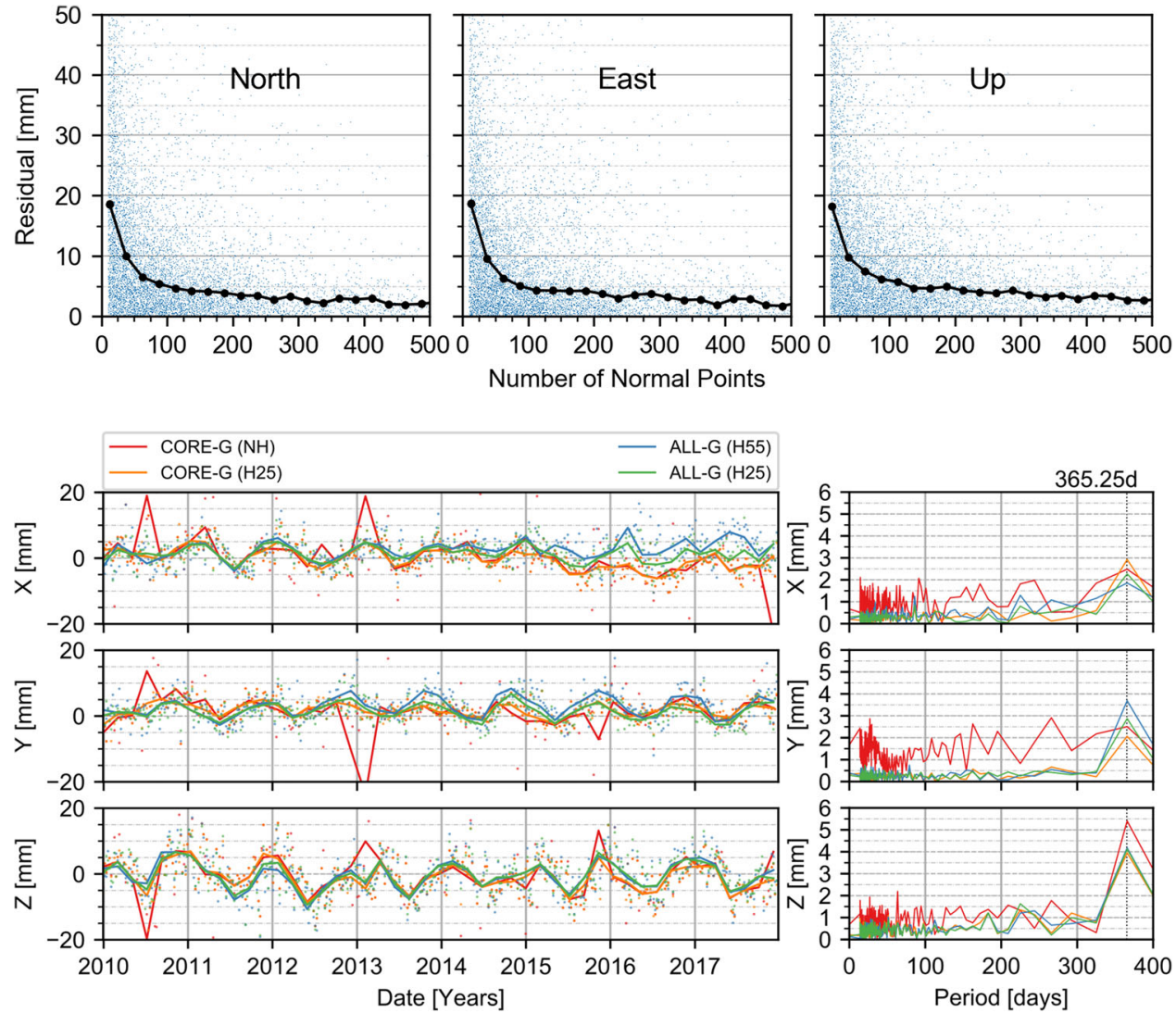

\subsubsection{Impact of using all available stations instead of core sites on the station coordinates}

We checked what is the impact of using different groups of datum-defining stations. We consider all possible stations for the datum definition instead of only stations, which are included in the ILRS list of core stations. The effect on the SCR depends on the threshold which is used to detect outlying stations and on the approach of the TRF datum realization in the solution. When using a more rigid threshold for 'ALL' solutions (up to $25 \mathrm{~mm}$ ), the SCR remains at a comparable level to the 'CORE' solutions, while the TRF realization is more robust because of the higher number of stations and a better geometry. By the example of CORE-G (H25) w.r.t. the ALL-G (H25) solution the IQR of the SCR changes from 10.9 to $11.4 \mathrm{~mm}, 11.7$ to $11.8 \mathrm{~mm}$ and 12.8 to $13.1 \mathrm{~mm}$, for the North, East and Up components, respectively. Thus, when the outlier rejection for the datum-defining stations is performed with a threshold of about $25 \mathrm{~mm}$, there is no need to define a list of core stations. All stations that pass the outlier rejection criterion can be considered as datum-defining without degradation of the SCR.

\subsubsection{Impact of station productivity on the station coordinate quality}

As described in Sect. 2, the selection process of datumdefining stations is based on the Helmert transformation. Only stations whose coordinate residuals do not exceed the assumed threshold are considered as datum-defining in the final parameter estimation. We checked whether the number of delivered normal points is connected with the residuals of station coordinates from the Helmert transformation.

Figure 11 illustrates the residuals for particular SLR stations as the function of the number of normal points delivered by stations in the weekly solutions. According to Fig. 11, the more observations delivered by stations in the weekly solution the higher the quality of the estimated coordinates. In general, 50 normal points per week are sufficient to deliver the coordinates, whose residuals w.r.t. the SLRF2014 are lower than $10 \mathrm{~mm}$ for all components. In total, 150 normal points lead to solutions with the median coordinate residuals below $5 \mathrm{~mm}$ for all components. After exceeding the value of 400 observations, the median residuals are at the level of 2-4 mm.

Most of the stations try to deliver as many observations as possible. On the other hand, there are many other circumstances which determine the quality of the delivered station coordinates and are station-specific. These include technol- 
Table 6 Numerical statistics for the GCC estimates and GCC formal errors

\begin{tabular}{|c|c|c|c|c|c|c|c|c|c|c|c|c|c|c|}
\hline \multirow[t]{2}{*}{ Solution } & & \multirow{2}{*}{$\begin{array}{l}X \\
\text { STD }\end{array}$} & \multicolumn{3}{|c|}{$\mathrm{X}$ formal error } & \multirow{2}{*}{$\begin{array}{l}\text { Y } \\
\text { STD }\end{array}$} & \multicolumn{3}{|c|}{ Y formal error } & \multirow{2}{*}{$\begin{array}{c}Z \\
\text { STD }\end{array}$} & \multicolumn{3}{|c|}{$\mathrm{Z}$ formal error } & \multirow[t]{2}{*}{ STA } \\
\hline & & & $50 \%$ & IQR & Perc & & $50 \%$ & IQR & Perc & & $50 \%$ & IQR & Perc & \\
\hline CORE-G & $(\mathrm{NH})$ & 8.2 & 0.9 & 0.7 & 13.2 & 13.9 & 0.9 & 0.6 & 13.6 & 7.1 & 1.6 & 0.7 & 15.1 & 9 \\
\hline CORE-G & (H55) & 2.1 & 0.9 & 0.6 & 8.1 & 1.8 & 0.9 & 0.5 & 7.9 & 2.6 & 1.6 & 0.6 & 9.8 & 9 \\
\hline CORE-G & (H45) & 2.0 & 0.9 & 0.5 & 7.2 & 1.8 & 0.9 & 0.4 & 7.7 & 2.6 & 1.6 & 0.6 & 8.6 & 9 \\
\hline CORE-G & (H35) & 1.9 & 0.9 & 0.5 & 5.5 & 2.0 & 0.9 & 0.4 & 6.5 & 2.7 & 1.6 & 0.6 & 6.9 & 9 \\
\hline CORE-G & (H25) & 1.7 & 0.9 & 0.5 & 4.5 & 1.5 & 0.9 & 0.4 & 5.0 & 2.5 & 1.6 & 0.6 & 6.0 & 9 \\
\hline CORE-G & (H15) & 1.8 & 0.8 & 0.4 & 1.7 & 1.3 & 0.8 & 0.3 & 3.6 & 2.5 & 1.5 & 0.5 & 3.8 & 9 \\
\hline CORE-G & (H10) & 2.0 & 0.8 & 0.4 & 1.2 & 1.4 & 0.8 & 0.3 & 2.9 & 2.5 & 1.5 & 0.5 & 3.3 & 8 \\
\hline ALL-G & $(\mathrm{NH})$ & 20.4 & 2.0 & 2.8 & 39.0 & 19.1 & 2.0 & 3.3 & 41.4 & 17.7 & 2.5 & 3.0 & 49.8 & 22 \\
\hline ALL-G & (H55) & 2.2 & 1.3 & 1.1 & 17.9 & 2.0 & 1.2 & 0.9 & 13.6 & 2.7 & 1.9 & 0.9 & 22.5 & 20 \\
\hline ALL-G & (H45) & 2.0 & 1.2 & 0.9 & 13.9 & 1.9 & 1.1 & 0.8 & 11.0 & 2.7 & 1.8 & 0.8 & 19.1 & 20 \\
\hline ALL-G & (H35) & 1.9 & 1.1 & 0.8 & 12.0 & 1.8 & 1.0 & 0.7 & 8.1 & 2.7 & 1.8 & 0.7 & 16.5 & 19 \\
\hline ALL-G & (H25) & 1.7 & 1.0 & 0.6 & 8.4 & 1.7 & 0.9 & 0.6 & 5.7 & 2.6 & 1.7 & 0.7 & 13.2 & 17 \\
\hline ALL-G & (H15) & 1.7 & 0.9 & 0.5 & 4.8 & 1.7 & 0.8 & 0.4 & 3.1 & 2.5 & 1.6 & 0.5 & 7.9 & 13 \\
\hline ALL-G & (H10) & 1.9 & 0.9 & 0.4 & 4.5 & 1.7 & 0.8 & 0.3 & 3.1 & 2.6 & 1.6 & 0.5 & 7.2 & 11 \\
\hline
\end{tabular}

'STD' denotes the standard deviation of the GCC residuals in reference to its 63-day averaged signal; 'IQR' denotes the inter-quartile range of GCC formal errors. ' $50 \%$ ' denotes the median value of GCC formal errors. 'Perc' denotes the percentage of epochs when the formal error exceed $2.5 \mathrm{~mm}$

ogy employed at the station (including the repetition rate), the geometry of the observations, models used for a normal point formation, and all systematic errors related to the station operation. The spread of the residual dots (see Fig. 11) in the range between 10-100 normal points goes from 0 to a few hundred mm, which shows that the station-specific issues are complex.

\subsection{Impact on the geocenter coordinates}

One of the main objectives of the ILRS is to analyze the changes of Earth's CoM relative to the global network and its time variations. The vector between CoM of the whole Earth system including all solid and fluid components and CoF of the solid Earth surface represented by the globally distributed set of stations is defined as the GCC (Blewitt 2003; Wu et al. 2012). However, the CoF is hardly available using the finite network of stations. Thus, the discussed GCC is more likely addressed to the $\mathrm{CoN}$ rather than $\mathrm{CoF}$, especially when an inhomogeneously distributed network of stations is employed in the solution. Couhert et al. (2018) indicated almost a $5 \mathrm{~mm}$ shift along with the $\mathrm{X}$ component of the GCC between SLR and DORIS solutions. On the other hand, Zajdel et al. (2019) found a network effect revealing a shift of $4 \mathrm{~mm}$ in the origin along the Y-axis between GNSS and SLR solutions. The estimation of the reliable GCC from SLR is crucial to deliver information about the mass change in the system Earth to the other techniques which are less sensitive to the geocenter motion, i.e., satellite altimetry, GNSS, or to support the GRACE-derived gravity field variations (Baur et al. 2013).

We calculate the 63-day mean values for each component of the geocenter coordinates to smooth the time series and separate the pronounced signals from the noise. Next, we compare the residuals of the particular solutions w.r.t. the 63day mean to see the variability of the particular estimates in reference to the main signal (see Fig. 12). In both 'ALL' and 'CORE' solutions, the lowest standard deviation of residuals occurs when the threshold of $25 \mathrm{~mm}$ is applied (see Table 6). The standard deviation of residuals is also consistent for CORE-G (H25) and ALL-G (H25) and equals approximately $1.7,1.5$, and $2.5 \mathrm{~mm}$ for the $\mathrm{X}$, Y, and $\mathrm{Z}$ components, respectively. The time series of GCC, which are computed in every solution, corresponds to each other (see Fig. 12), especially before 2014 when the SLRF2014 was used as the a priori TRF in the processing. SLR station coordinates after 2014 are based on the extrapolation, thus worsen with time, especially in the case of stations with a short history of the coordinate time series ${ }^{9}$ (e.g., Mendeleevo, 1874; Brasilia, 7407). Moreover, stations with unexpected nonlinear events in the station motion affect the geocenter estimates. Interestingly, the time series of the X component of the GCC in both ALL-G (H55) and ALL-G (H25) solutions start to systematically diverge from the 'CORE' solutions after 2015. These changes may result from the fact that more stations with uncertain quality were accepted in the datum realiza-

\footnotetext{
9 ftp://cddis.nasa.gov/slr/products/resource/SLRF2014_POS+VEL_2030. 0_180504.snx.
} 


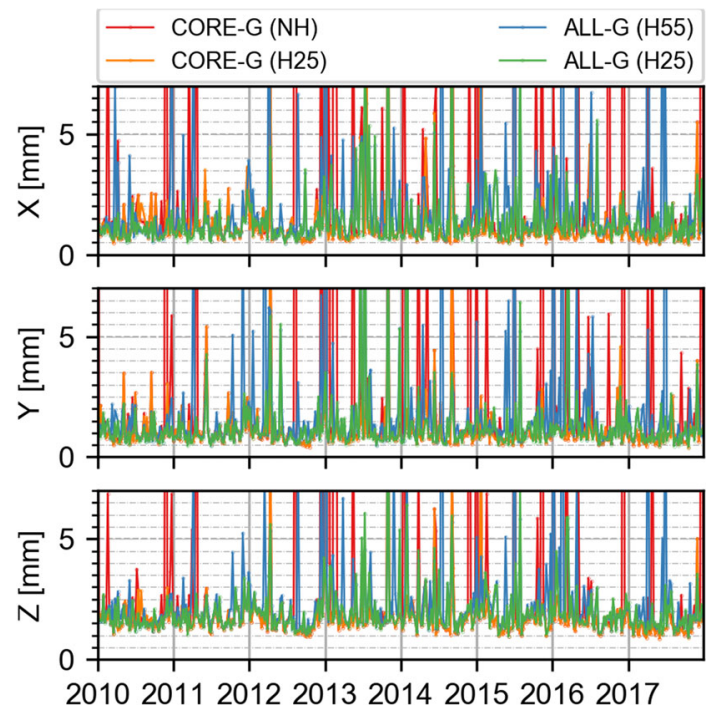

Fig. 13 Time series of the formal errors of GCC estimates

tion (see Fig. 12). The differences are also visible in the time series of formal errors (see Fig. 13). In general, the median errors are at the comparable level between the solutions (see Table 6). The median error equals approximately 1.0, 1.0 and $1.6 \mathrm{~mm}$, for the $\mathrm{X}, \mathrm{Y}$ and $\mathrm{Z}$ component, respectively.

Using more stations does not decrease the formal error of estimated geocenter coordinates (see Table 6). However, there are different epochs with increased values of formal errors of geocenter estimation (see Fig. 13) which are caused by the inappropriate geometry of datum-defining stations or a bad coordinate solution for a particular station that was accepted for the TRF datum realization. We calculated the percentage of epochs when the formal error of the particular geocenter components exceeds the threshold of $2.5 \mathrm{~mm}$. In general, the more rigorous threshold for the selection of datum-defining stations, the fewer epochs when formal errors drastically increase. In the 'CORE' group, the number of outlying epochs decreases from 13.2 to $1.2 \%, 13.6$ to $2.9 \%$, 15.1 to $3.3 \%$ from 'NH' to 'H10' for the $\mathrm{X}, \mathrm{Y}$, and Z component, respectively. In 'ALL' group, the number of outlying epochs decreases from 39.0 to $4.5 \%, 41.4$ to $3.1 \%, 49.8$ to $7.2 \%$, respectively. For 'ALL' solutions, we have to apply the threshold of 15-25 mm to receive a comparable percentage level of outlying epochs as for the CORE-G (H55) solution.

The amplitudes of the most pronounced annual signal in the GCC estimates differ between the particular solutions. The amplitude of the annual signal in ALL-G (H25) (17 stations) is higher by 1.0 and $0.2 \mathrm{~mm}$ for the $\mathrm{Y}$ and $\mathrm{Z}$ components, respectively, when compared to CORE-G (H25) (9 stations) (see Fig. 12). On the other hand, the amplitude of the annual signal for the $\mathrm{X}$ component is lower by about 1.0 $\mathrm{mm}$ in ALL-G (H25) than in CORE-G (H25).
Table 7 Statistics of differences between PM series obtained using either NNR (solution 'NG') or NNR+NNT (solution 'O'), in the particular solutions

\begin{tabular}{|c|c|c|c|c|c|}
\hline \multirow[t]{2}{*}{ Solution } & & \multicolumn{2}{|c|}{$X(\mu$ as $)$} & \multicolumn{2}{|c|}{$\mathrm{Y}(\mu \mathrm{as})$} \\
\hline & & Mean & IQR & Mean & IQR \\
\hline CORE & $(\mathrm{NH})$ & -373 & 770 & -28 & 179 \\
\hline CORE & (H55) & -8 & 71 & 29 & 88 \\
\hline CORE & (H25) & -4 & 65 & 25 & 83 \\
\hline ALL & $(\mathrm{NH})$ & -97 & 424 & -17 & 384 \\
\hline ALL & (H55) & -20 & 109 & 23 & 117 \\
\hline ALL & (H25) & -16 & 69 & 14 & 83 \\
\hline
\end{tabular}

In both solutions, the GCC are not estimated

\subsection{Impact on Earth rotation parameters}

The TRF datum realization is essential for the high quality of the ERP estimates. First of all, it is crucial to underline the expected differences between the ERP estimates derived from the solutions ' $\mathrm{NG}$ ', ' $\mathrm{G}$ ', and ' $\mathrm{O}$ '. There is no difference between the ERP estimates in the solutions ' $N G$ ' and ' $G$ ' in which station coordinates are expressed in different frames ( $\mathrm{CoM}$ or $\mathrm{CoN}$ ) shifted by the GCC, whereas the satellite orbits and other parameters are equal (see Sects. 3.1 and 2.1). On the other hand, the differences are expected between the solutions ' $\mathrm{NG}$ ' and ' $\mathrm{O}$ ', because of the correlations that exist between the rotations and translations of a nonuniformly distributed network and over-constraining of the solution ' $\mathrm{O}$ '. The ' $\mathrm{O}$ ' solution suppresses geocenter motion that must be distributed among all estimated parameters except for station coordinates because of NNT. Therefore, only solutions which are based on the 'NG' and 'O' approaches are described in this section.

Table 7 summarizes the statistics of differences between the pole coordinate estimates derived in the ' $\mathrm{NG}$ ' and ' $\mathrm{O}$ ' solutions. The IQR of differences are greater than 60 and $80 \mu$ as for the $\mathrm{X}$ and $\mathrm{Y}$ pole coordinate, respectively. These results are higher than those indicated by Ray et al. (2017) and Zajdel et al. (2019) for GNSS solutions. The large differences confirm the presumption that in the case of an inhomogeneously distributed set of the datum-defining stations the ERPs are strongly affected. The difference between the particular solutions decreases when the outlying stations are properly rejected from the TRF datum realization. The IQR of the $\mathrm{X}$ pole coordinate differences ranges from 770 to $65 \mu$ as for CORE (NH) and CORE (H25) (see Table 7). In the case of the $\mathrm{Y}$ pole coordinates, the differences decrease from 179 to $83 \mu$ as for CORE (NH) and CORE (H25).

Table 8 shows the mean offset and weighted root mean square (WRMS) of the pole coordinates and LoD estimates in reference to the a priori IERS-14-C04 series (Bizouard et al. 2018). The WRMS values are calculated based on equation 1 , where $x_{\text {IIERS }}-x_{i}$ represent the difference between 
Table 8 Statistics of the estimated X, Y pole coordinates and LoD in reference to the a priori IERS-14-C04 series
Fig. 14 The time series of ERPs from the particular solutions

\begin{tabular}{|c|c|c|c|c|c|c|c|c|}
\hline \multirow[t]{2}{*}{ Solution } & & \multicolumn{2}{|c|}{$X(\mu$ as $)$} & \multicolumn{2}{|c|}{$\mathrm{Y}[\mu \mathrm{as}]$} & \multicolumn{2}{|c|}{ LoD ( $\mu \mathrm{s} /$ day $)$} & \multirow[t]{2}{*}{ STA } \\
\hline & & Mean & WRMS & Mean & WRMS & Mean & WRMS & \\
\hline CORE-NG & $(\mathrm{NH})$ & 7 & 402 & 78 & 650 & -80 & 120 & 9 \\
\hline CORE-NG & (H55) & 27 & 182 & 86 & 188 & -80 & 120 & 9 \\
\hline CORE-NG & (H45) & 31 & 172 & 86 & 187 & -80 & 120 & 9 \\
\hline CORE-NG & (H35) & 33 & 166 & 84 & 187 & -80 & 120 & 9 \\
\hline CORE-NG & $(\mathrm{H} 25)$ & 31 & 164 & 82 & 172 & -80 & 120 & 9 \\
\hline CORE-NG & (H15) & 30 & 162 & 74 & 167 & -80 & 120 & 9 \\
\hline CORE-NG & (H10) & 29 & 158 & 77 & 165 & -80 & 120 & 8 \\
\hline ALL-NG & $(\mathrm{NH})$ & -321 & 1248 & 55 & 744 & -80 & 118 & 22 \\
\hline ALL-NG & (H55) & -1 & 170 & 62 & 187 & -80 & 120 & 20 \\
\hline ALL-NG & (H45) & 0 & 165 & 73 & 178 & -80 & 120 & 20 \\
\hline ALL-NG & (H35) & 10 & 164 & 74 & 166 & -80 & 120 & 19 \\
\hline ALL-NG & $(\mathrm{H} 25)$ & 27 & 160 & 83 & 161 & -80 & 118 & 17 \\
\hline ALL-NG & (H15) & 32 & 156 & 84 & 164 & -80 & 118 & 13 \\
\hline ALL-NG & (H10) & 24 & 160 & 86 & 174 & -80 & 118 & 11 \\
\hline CORE-O & $(\mathrm{NH})$ & 25 & 192 & 46 & 203 & -86 & 123 & 9 \\
\hline CORE-O & (H55) & 35 & 164 & 57 & 165 & -84 & 120 & 9 \\
\hline CORE-O & (H25) & 36 & 156 & 57 & 159 & -85 & 120 & 9 \\
\hline ALL-O & $(\mathrm{NH})$ & -235 & 1061 & 86 & 518 & -89 & 139 & 22 \\
\hline ALL-O & (H55) & 18 & 181 & 43 & 207 & -89 & 123 & 20 \\
\hline ALL-O & $(\mathrm{H} 25)$ & 41 & 164 & 71 & 169 & -86 & 122 & 17 \\
\hline
\end{tabular}
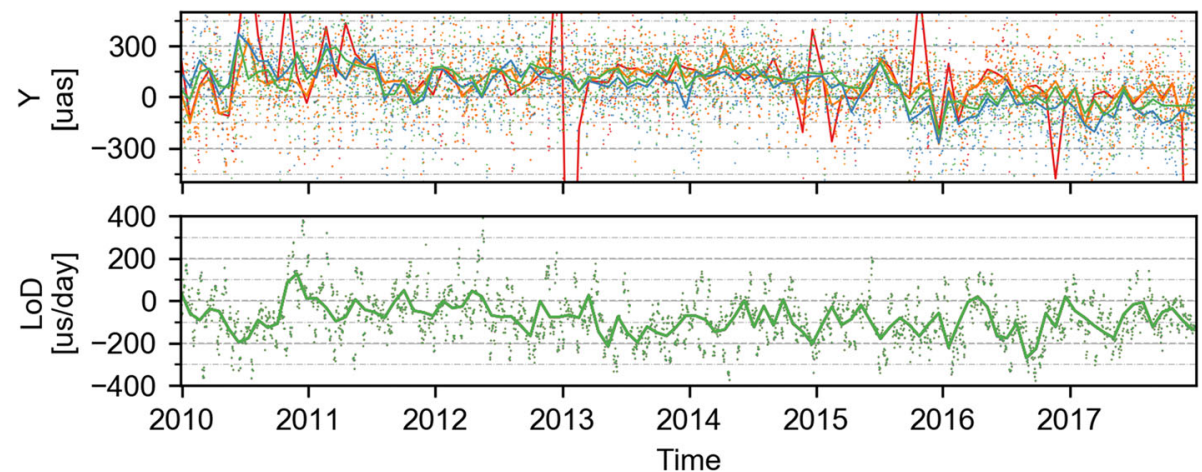

the estimated ERP parameter at the epoch $i$ and the corresponding value from the IERS-14-C04 time series, and $w_{i}$ is the weight for the particular element, which is calculated as the squared inverse of the parameter formal error.

$\operatorname{WRMS}(x)=\sqrt{\frac{\sum_{i=1}^{n}\left(x_{i I E R S}-x_{i}\right)^{2} * w_{i}}{\sum_{i=1}^{n} w_{i}}}$
In both groups of 'CORE' and 'ALL' solutions, the results for 'NH' have the worst quality (see Table 8). The first issue visible in the time series of the pole coordinates is the leap in the values, which occurred approximately at the end of 2015 (see Fig. 14). The leap equals to approximately $200 \mu$ as and $-100 \mu$ as, for the $\mathrm{X}$ pole and $\mathrm{Y}$ pole coordinates, respectively. The leap is also visible in the time series of ERP 
delivered by the particular ACs ${ }^{10}$ or Associated ACs (Otsubo et al. 2018). The change in the pole coordinates corresponds with the drop in the efficiency of the McDonald (7080, USA) station. Hence, the lack of the homogeneously distributed stations and observations affects the ERP estimates.

There are no significant differences in the statistics between the particular solutions within the group of the 'CORE' solutions because only single stations were occasionally rejected and the geometry is consistent between the solutions. Furthermore, when we properly reject the outlying stations in the ALL-NG (H25) solution, the statistics of the differences roughly correspond to each other in the 'CORE' and 'ALL' solutions (see Table 8). The mean offset is at the level of 30 and $80 \mu$ as for the $\mathrm{X}$ and $\mathrm{Y}$ pole coordinates, respectively. Drożdżewski et al. (2019) found that $20 \mu$ as of the offset in the $\mathrm{X}$ and $\mathrm{Y}$ pole coordinates can be explained by neglecting horizontal gradients in the troposphere delay modeling in the SLR processing. Besides, WRMS is at the level of 160-180 $\mu$ as for the both $\mathrm{X}$ and $\mathrm{Y}$ pole coordinates. In the case of the LoD, the mean offset and the WRMS equal -80 and $120 \mu \mathrm{s} /$ day. Because of the PWL parametrization and rigid constraining for the middle UT1-UTC value, there are almost no differences between the particular solutions in the case of the LoD estimates.

The differences are visible for the solutions within the group of ALL-NG solutions. When the quite loose threshold is applied for the rejection of datum-defining stations, e.g., ALL-NG (H45) the mean offset of the X pole coordinate w.r.t the IERS-14-C04 reaches $0 \mu$ as. The quality of the ERPs is sensitive to the global distribution of the datum-defining network, and the continuity of the observations in time. This is why the GNSS technique, with a homogeneously distributed network of stations, is the most appropriate for this purpose, among the other geodetic techniques. Using more SLR stations in the TRF datum realization improves the distribution of the stations and therefore the mean offset w.r.t. the IERS14-C04 also decreases.

Finally, both CORE-NG and CORE-O are consistent w.r.t. the IERS-14-C04 at the comparable level. In the case of the CORE-O (H25) solution, the mean offset and WRMS equal 36 and $156 \mu$ as, 57 and $159 \mu$ as, -85 and $120 \mu$ s/day, for the $\mathrm{X}$ and $\mathrm{Y}$ pole coordinates and LoD, respectively. We see that the statistics are superior in the over-constained CORE-O (H25) when compared with CORE-NG (H25). The greatest improvement is visible for the mean offset of the $\mathrm{Y}$ pole coordinate as it decreases by approximately $25 \mu$ as between the corresponding CORE-O and CORE-NG solutions, although the same set of datum-defining stations were taken into account. However, we have to be aware of the processing details, which probably cause these changes. In the solution ' $\mathrm{O}$ ', the geocenter motion is ignored and improp-

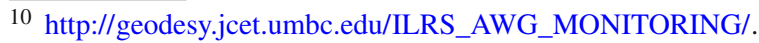

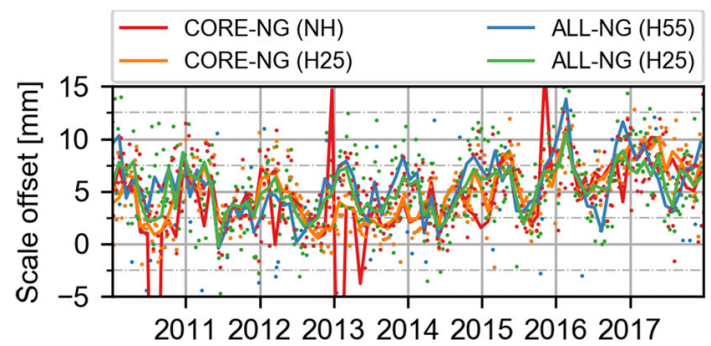

Fig. 15 Time series of scale differences between the estimates from the particular solutions and the ITRF2014 scale

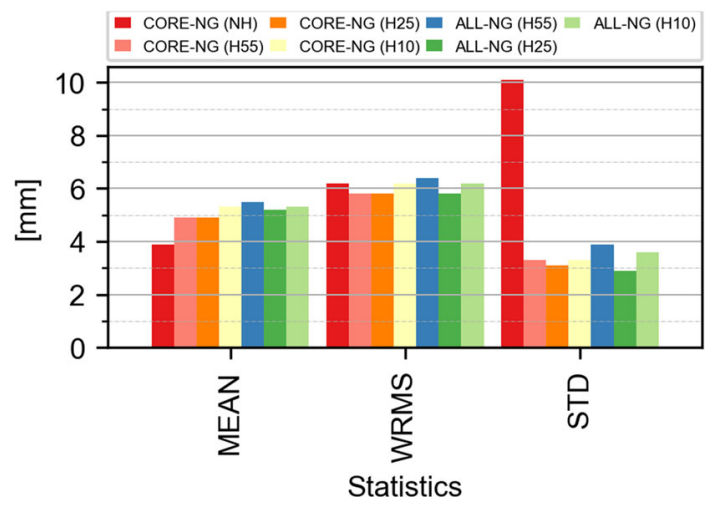

Fig. 16 Mean scale offsets with respect to the ITRF2014 scale from different LAGEOS solutions. WRMS denotes weighted root mean square. STD denotes standard deviation

erly handled. In such a processing model, we assume that the origin of the TRF and the Earth CoM as seen by satellite orbits coincide in the same point (Dach et al. 2014). The geocenter signal is suppressed and then partly spread over station coordinates, ERPs and LAGEOS orbits, and increases the observational residuals. Thus, we may conclude that the solution ' $\mathrm{O}$ ' is conceptually wrong for the precise orbit determination and the SLR datum realization.

\subsection{Impact on the terrestrial scale}

The terrestrial scale is one of the major products delivered from the SLR observations to LAGEOS-1 and LAGEOS-2. This test shows how the change of the station distribution, which participate in the TRF datum realization, affects the quality of the scale realization. Figure 15 illustrates the time series of weekly scale estimates delivered from particular solutions. The scale is compared to the SLRF2014. The SLRF2014 scale is consistent with the ITRF2014 scale which is based on the combination of long-term SLR and VLBI solutions. Some SLR stations are affected by biases which are currently investigated by the ILRS; thus, a bias in the scale from this study is also present in the estimates.

Figure 16 shows the summarized statistics, including the mean, WRMS, and standard deviations. We can interpret the standard deviation and WRMS as the indicators of the param- 
Table 9 Statistics of the estimated $\mathrm{X}$, Y pole coordinates and LoD for CORE-G (H25) and CONA-G $(\mathrm{H} 25)$ in reference to the a priori IERS-14-C04 series

\begin{tabular}{|c|c|c|c|c|c|c|c|}
\hline \multirow[t]{2}{*}{ Solutions } & & \multicolumn{2}{|c|}{$X(\mu$ as $)$} & \multicolumn{2}{|c|}{$\mathrm{Y}[\mu \mathrm{as}]$} & \multicolumn{2}{|c|}{$\operatorname{LoD}(\mu \mathrm{s} /$ day $)$} \\
\hline & & Mean & WRMS & Mean & WRMS & Mean & WRMS \\
\hline CORE-G & (H25) & 31 & 164 & 82 & 172 & -80 & 120 \\
\hline CONA-G & (H25) & 58 & 452 & 150 & 354 & -80 & 120 \\
\hline
\end{tabular}

eter stability, while the mean offset indicates the consistency w.r.t. the a priori SLRF2014 frame. Based on Fig. 16, we see that all the solutions are roughly consistent, which proves that the scale estimates, which are delivered from the group of 'ALL' solutions are of good quality, even despite using stations which are not as reliable as the core sites. The WRMS is at the level of $5.8 \mathrm{~mm}$ for both CORE-NG (H25) and ALL-NG (H25) solutions. However, when outlying stations are not rejected from the TRF datum realization, such as in CORE-NG (NH), single epochs are deteriorated. The standard deviation for the solution CORE-NH is more than three times larger than for the solution CORE-NG (H25) (Fig. 16). The mean offset is at the level of $5 \mathrm{~mm}$ for all the solutions. However, the scale estimates systematically increase after 2014, independently from the solutions based on 'CORE' and 'ALL' groups of SLR stations. The linear change of the scale after 2014 is a consequence of the aging of the current a priori TRF. Moreover, the SLR stations with a short time series of the coordinates in the SLRF2014 are condemned to the lower quality of a priori coordinates. The mean offset at the level of $5 \mathrm{~mm}$ is also caused by the station satellitespecific range biases ${ }^{11}$ and the Blue-Sky effect caused by neglected atmospheric loading station displacements (Bury et al. 2019b).

\subsection{Distribution of stations in the TRF datum realization}

Finally, we investigate the impact of the network effect in the TRF datum realization on ERPs and GCC estimates. We prepare an additional solution marked as CONA-G (H25), which is consistent in methodology with CORE-G (H25); however, the Australian stations (7090, Yarragadee and 7825, Mount Stromlo) are exempted from the TRF datum realization. Hence, the TRF is based mostly on the European stations, while the southern hemisphere representation is limited to the station 7501 (Hartebeesthoek, South Africa), whereas coordinates of Australian stations are estimated as free parameters without any constraints.

First, we have calculated the differences between the GCC delivered in the CONA-G (H25) and CORE-G (H25) solutions (see Fig. 17). The mean and the standard deviation of the residuals are at the level of $4 \pm 9,4 \pm 9$ and $3 \pm 6 \mathrm{~mm}$ for the

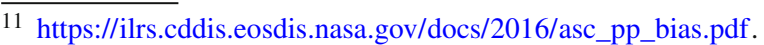
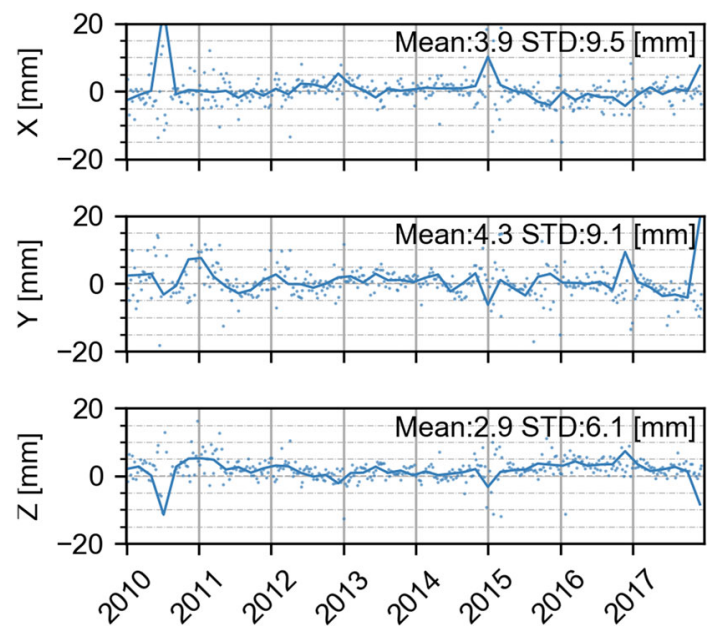

Fig. 17 Time series of the differences in the GCC estimates between CORE-G (H25) (a standard solution) and CONA-G (H25) (excluding Australian stations)
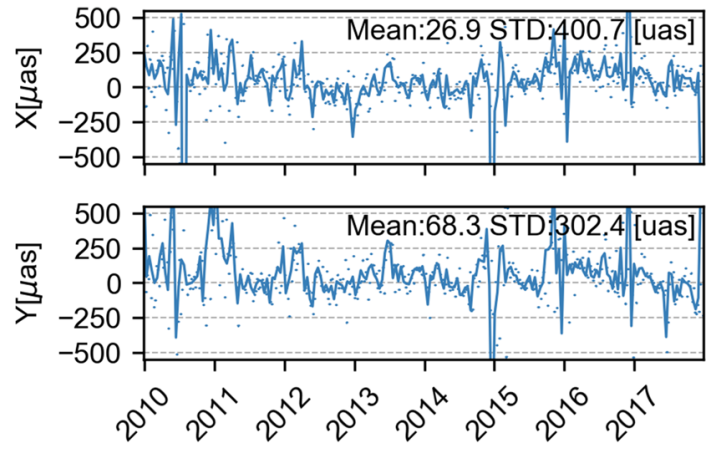

Fig. 18 Time series of the differences in the pole coordinate estimates between CORE-G (H25) and CONA-G (H25)

$\mathrm{X}, \mathrm{Y}$, and Z components, respectively. The main geophysical annual signal is also decreased by approximately $2.2 \mathrm{~mm}$ for the GCC-Y component. Surprisingly, the Z component of the GCC is the least affected. The information on the geocenter motion signal is in general well reconstructed despite the deficiency of datum-defining stations in the southern hemisphere. On the other hand, the reliability of the GCC parameters deteriorates as the median errors increase by about $0.5,0.8$ and $0.2 \mathrm{~mm}$ for the $\mathrm{X}, \mathrm{Y}$ and $\mathrm{Z}$ components, respectively. The percentage of epochs with the outlying formal errors, which exceed $2.5 \mathrm{~mm}$, increases from 4 to $19 \%, 5$ to $25 \%$, and 6 to $20 \%$ for the $\mathrm{X}, \mathrm{Y}$, and $\mathrm{Z}$ component, respectively. 
In the case of ERPs, we compare two aforementioned solutions between each other and with the a priori IERS14-C04 series. The differences between the ERPs are mainly visible for the pole coordinates, hence the LoD parameter is not shown here. The mean and the standard deviation of the differences between 'CORE' and 'CONA' solutions equal $27 \pm 401$ and $68 \pm 302 \mu$ as, for the $X$ and $Y$ coordinates, respectively (see Fig. 18). When compared with the IERS-14-C04 series, the mean offset and the standard deviation increase for 'CONA' w.r.t 'CORE' solution from $31 \pm 164$ to $58 \pm 452 \mu$ as and from $82 \pm 172$ to $150 \pm 354 \mu$ as for the $\mathrm{X}$ and $\mathrm{Y}$ pole coordinates, respectively (see Table 9). This shows that the distribution of the stations in the TRF datum realization substantially affects the quality of the SLR-based products, especially the pole coordinates.

\section{Conclusions}

In response to the four main questions raised in the motivation part of this work, a series of analyses have been conducted. We showed differences in the station coordinates, the scale of the realized TRF, ERPs and GCC which may arise from using different approaches of the TRF datum realization and the selection of datum sites.

The ILRS recommends using most stable core sites for the TRF realization in the SLR processing. We tried to find out if any stations outside the list of core sites are suitable for the TRF datum realization. All the stations, which are currently classified as core stations by the ILRS, were very stable over time. According to the station selection algorithm, which was based on the Helmert transformation, we found that some of the stations such as 7827 (SOS-W Wettzell, Germany), 7110 (Monument Peak, USA), 7237 (Changchun, China), 8834 (WLRS Wettzell, Germany), 7845 (Grasse, France), 7124 (Tahiti, French Polynesia), 7406 (San Juan, Argentina), 1888 (Svetloe, Russia), and 1890 (Badary, Russia) were accepted for the TRF datum realization in more than $80 \%$ of their occurrences when a $25 \mathrm{~mm}$ threshold was applied for stationoutlier selection.

Next, we checked three different approaches to the TRF realization using MCs: (1) applying only NNR conditions, while the GCC are constrained to zero (solutions 'NG'), (2) applying both NNR+NNT and the simultaneous estimation of the GCC (solutions ' $G$ '), (3) applying both NNR+NNT, while the GCC are constrained to zero (solutions ' $\mathrm{O}$ '). Using NNR+NNT constraints instead of NNR-only decreases the SCR because the geocenter motion is not included in the station coordinates. Looking at the individual stations, the improvement is larger for those stations, which participated in the TRF datum realization, than for the other stations. Furthermore, the impact is more visible for the Up compo- nent when compared to the North and East, components. By the example of CORE (H25) solution, the improvement of SCR for core sites is at the level of $11 \%, 8 \%$, and $20 \%$, for the North, East and Up components, respectively. On the other hand, we have to be aware that the increased SCR in the NNR solution inherently originates from the signal of the geocenter motion included in the station coordinates. Besides, the SLR observations to the geodetic satellites are undoubtedly predisposed to deliver station coordinates in $\mathrm{CoM}$ frame. In terms of the comparison between the ' $\mathrm{G}$ ' and ' $\mathrm{O}$ ' solutions, we see that they roughly correspond to each other. If we over-constrain the solution and do not estimate the GCC as a parameter, we influence the station coordinates and increase the a posteriori RMS of unit weight by up to a few percents. The translation of the origin of the CORE-O (H25) w.r.t the CORE-G (H25) remains well below $1 \mathrm{~mm}$. However, the RMS of the Helmert transformation is at the level of $4.0 \pm 2.8 \mathrm{~mm}$. On the other hand, the difference between ' $\mathrm{O}$ ' and ' $\mathrm{G}$ ' solution is visible for the ERP estimates. Depending on the adopted set of datumdefining stations, the IQR of differences are greater than 60 and $80 \mu$ as for the $\mathrm{X}$ and $\mathrm{Y}$ pole coordinates, respectively.

We found that about 50 normal points per week per station are needed to deliver station coordinates with the accuracy better than $10 \mathrm{~mm}$ for the North, East and Up components. 150 normal points lead to solutions with the median coordinate residuals below $5 \mathrm{~mm}$, whereas for 400 observations the median is about $2-4 \mathrm{~mm}$. Therefore, the high productivity of SLR stations is indispensable for the high-quality TRF datum realizations.

We can even double the number of the datum-defining stations in the TRF datum realization when using all available SLR stations instead of only 'CORE' stations. However, outlying stations have to be eliminated from the TRF datum realization, for example, using a more rigid threshold while testing the stations employing the Helmert transformation. Otherwise, using unreliable stations could worsen the TRF datum realization and the quality of other parameters being estimated. For the 'ALL' solution, we can deliver the station coordinates with the quality at the comparable level to that of the 'CORE' solutions, when the sufficiently restrictive threshold is applied. The $25 \mathrm{~mm}$ threshold is considered to be optimal to both eliminate the epoch-wise temporal deviations in the SLR-based products and not to decrease the number of datum-defining stations. By the example of CORE-G (H25) w.r.t. the ALL-G (H25) solution the IQR of the SCR changes from 10.9 to $11.4 \mathrm{~mm}, 11.7$ to $11.8 \mathrm{~mm}$ and 12.8 to $13.1 \mathrm{~mm}$, for the North, East and Up components, respectively. Moreover, whichever alternative solution is chosen, the leap in the time series of the pole coordinates is visible at the end of 2015. The leap roughly corresponds to a decrease in the efficiency of the 7080 stations (McDonald, USA), which could 
undermine the distribution of well-performing sites in North America and affect the estimates of the pole coordinates. Because of the limited number of both well-performing and stable in time SLR sites, losing a single core site in the strategic areas may thus deteriorate the SLR-based products. To investigate the impact of the station loss in the TRF datum realization, we tested what would happen if we exclude two Australian stations (i.e., 7090 and 7825) from the TRF datum realization. The quality of the ERPs and the GCC delivered in that approach is of much worse quality than in the corresponding 'CORE' solution, e.g., WRMS of the X pole coordinate increased from 164 to $452 \mu$ as. Using a welldistributed set of datum-defining SLR sites is thus crucial.

Employing all available sites, instead of the ILRS core stations only, may slightly improve the quality of the SLRderived products. However, there is a need for a better quality of the a priori coordinates for new SLR stations in SLRF. The new realization of the ITRF should improve the quality for the most of the stations, then the experiment could be repeated and extended. In this contribution, SLRF2014 frame was only used as the a priori TRF. However, the analyses could be extended to examine the differences when other realizations of the ITRS are used, i.e., DTRF2014 (Seitz et al. 2016) or JTRF2014 (Abbondanza et al. 2017). That would allow for investigating the quality of ERPs and GCC in different TRFs.

Acknowledgements ILRS society is acknowledged for providing SLR data and maintaining the SLR network. ILRS ASC is acknowledged for constant development of SLR-based products. The SLR LAGEOS-1/2 normal point data were obtained through the online archives of the Crustal Dynamics Data Information System (CDDIS), NASA Goddard Space Flight Center, Greenbelt, MD, USA (Noll et al. 2018).

Author contributions All the authors contributed to the design of the study. RZ and KS came up with the idea of the study. RZ carried out the experiments and drafted the manuscript. MD provided normal equations based on the SLR observations to LAGEOS-1/-2. KS, GB and DS participated in the experimental analysis. All authors read and approved the final manuscript.

Funding K. Sośnica, M. Drożdżewski, and G. Bury are supported by the National Science Centre, Poland $(\mathrm{NCN})$, grant no. UMO2015/17/B/ST10/03108. K. Sośnica, R. Zajdel and D. Strugarek are supported by the National Science Centre, Poland (NCN), grant no. UMO-2018/29/B/ST10/00382.

\section{Compliance with ethical standards}

Conflict of interest The authors declare that they have no competing interests.

Open Access This article is distributed under the terms of the Creative Commons Attribution 4.0 International License (http://creativecomm ons.org/licenses/by/4.0/), which permits unrestricted use, distribution, and reproduction in any medium, provided you give appropriate credit to the original author(s) and the source, provide a link to the Creative Commons license, and indicate if changes were made.

\section{References}

Altamimi Z, Rebischung P, Métivier L, Collilieux X (2016) ITRF2014: a new release of the International Terrestrial Reference Frame modeling nonlinear station motions. J Geophys Res Solid Earth 121(8):6109-6131. https://doi.org/10.1002/2016JB013098

Angermann D, Müller H (2009) On the strength of SLR observations to realize the scale and origin of the terrestrial reference system. In: Observing our changing earth. Springer, Berlin, pp 21-29. https:// doi.org/10.1007/978-3-540-85426-5-3

Appleby G, Otsubo T, Pavlis E, Luceri V, Sciarretta C (2012) Improvements in systematic effects in satellite laser ranging analysessatellite centre-of-mass corrections. In: EGU general assembly conference abstracts, vol 14, p 11566

Appleby G, Rodríguez J, Altamimi Z (2016) Assessment of the accuracy of global geodetic satellite laser ranging observations and estimated impact on ITRF scale: estimation of systematic errors in LAGEOS observations 1993-2014. J Geod 90(12):1371-1388. https://doi.org/10.1007/s00190-016-0929-2

Arnold D, Montenbruck O, Hackel S, Sośnica K (2018) Satellite laser ranging to low Earth orbiters: orbit and network validation. J Geod. https://doi.org/10.1007/s00190-018-1140-4

Baur O, Kuhn M, Featherstone WE (2013) Continental mass change from GRACE over 2002-2011 and its impact on sea level. J Geod 87(2):117-125. https://doi.org/10.1007/s00190-012-0583-2

Bizouard C, Lambert S, Gattano C, Becker O, Richard JY (2018) The IERS EOP 14C04 solution for Earth orientation parameters consistent with ITRF 2014. J Geod. https://doi.org/10.1007/s00190018-1186-3

Blewitt G (2003) Self-consistency in reference frames, geocenter definition, and surface loading of the solid earth. J Geophys Res Solid Earth. https://doi.org/10.1029/2002JB002082

Blewitt G (2015) Terrestrial reference frame requirements for studies of geodynamics and climate change. In: van Dam T (eds) REFAG 2014. International association of geodesy symposia, vol 146. Springer, Cham. https://doi.org/10.1007/1345-2015-142

Blewitt G, Heflin MB, Webb FH, Lindqwister UJ, Malla RP (1992) Global coordinates with centimeter accuracy in the International Terrestrial Reference Frame using GPS. Geophys Res Lett 19(9):853-856. https://doi.org/10.1029/92GL00775

Bloßfeld M, Seitz M, Angermann D (2014) Non-linear station motions in epoch and multi-year reference frames. J Geod 88(1):45-63. https://doi.org/10.1007/s00190-013-0668-6

Bloßfeld M, Štefka V, Müller H, Gerstl M (2015) Satellite laser ranging. In: IAG SYMPOSIA, vol 143. https://doi.org/10.1007/13452015-202

Bloßfeld M, Rudenko S, Kehm A, Panafidina N, Müller H, Angermann D, Hugentobler U, Seitz M (2018) Consistent estimation of geodetic parameters from SLR satellite constellation measurements. J Geod 92(9):1003-1021. https://doi.org/10.1007/s00190018-1166-7

Bock D, Noomen R, Scherneck HG (2005) Atmospheric pressure loading displacement of SLR stations. J Geodyn 39(3):247-266. https://doi.org/10.1016/J.JOG.2004.11.004

Bury G, Sośnica K, Zajdel R (2019a) Multi-GNSS orbit determination using satellite laser ranging. J Geod. https://doi.org/10.1007/ s00190-018-1143-1

Bury G, Sośnica K, Zajdel R (2019b) Impact of the atmospheric non-tidal pressure loading on global geodetic parameters based on Satellite Laser Ranging to GNSS. IEEE Trans Geosci Remote Sens 57(6):3574-3590. https://doi.org/10.1109/TGRS. 2018.2885845

Collilieux X, Altamimi Z (2009) Impact of the network effect on the origin and scale: case study of satellite laser ranging. In: Observing 
our changing earth. Springer, Berlin, pp 31-37. https://doi.org/10. 1007/978-3-540-85426-5-4

Couhert A, Mercier F, Moyard J, Biancale R (2018) Systematic error mitigation in DORIS-derived geocenter motion. J Geophys Res Solid Earth 123(11):10142-10161. https://doi.org/10.1029/ 2018JB015453

Coulot D, Pollet A, Collilieux X, Berio P (2010) Global optimization of core station networks for space geodesy: application to the referencing of the SLR EOP with respect to ITRF. J Geod 84(1):31-50. https://doi.org/10.1007/s00190-009-0342-1

Dach R, Schaer S, Hugentobler U, Rodríguez-Solano CJ, Lutz S, Steigenberger $P$ et al (2014) Estimating the geocenter from GNSS data. In: IGS workshop 2014. Pasadena, California, USA. 23.06.27.06.2014. https://doi.org/10.7892/boris.57789

Dong D, Yunck T, Heflin M (2003) Origin of the international terrestrial reference frame. J Geophys Res Solid Earth. https://doi.org/10. 1029/2002JB002035

Dow JM, Neilan RE, Rizos C (2009) The International GNSS Service in a changing landscape of Global Navigation Satellite Systems. J Geod 83(3-4):191-198. https://doi.org/10.1007/s00190008-0300-3

Drożdżewski M, Sośnica K (2018) Satellite laser ranging as a tool for the recovery of tropospheric gradients. Atmos Res 212:33-42. https:// doi.org/10.1016/J.ATMOSRES.2018.04.028

Drożdżewski M, Sośnica K, Zus F, Balidakis K (2019) Troposphere delay modeling with horizontal gradients for satellite laser ranging. J Geod. https://doi.org/10.1007/s00190-019-01287-1

Eanes RJ (2004) CSR4.0A global ocean tide model. Center for Space Research, University of Texas, Austin

Glaser S, Fritsche M, Sośnica K, Rodríguez-Solano CJ, Wang K, Dach R, Hugentobler U, Rothacher M, Dietrich R (2015) A consistent combination of GNSS and SLR with minimum constraints. J Geod 89(12):1165-1180. https://doi.org/10.1007/s00190-015-0842-0

Glaser S, König R, Neumayer KH, Nilsson T, Heinkelmann R, Flechtner F, Schuh H (2018) On the impact of local ties on the datum realization of global terrestrial reference frames. J Geod. https:// doi.org/10.1007/s00190-018-1189-0

Guo J, Wang Y, Shen Y, Liu X, Sun Y, Kong Q (2018) Estimation of SLR station coordinates by means of SLR measurements to kinematic orbit of LEO satellites. Earth Planets Space 70(1):201. https://doi. org/10.1186/s40623-018-0973-7

Hattori A, Otsubo T (2019) Time-ing solar radiation pressure on Ajisai in comparison with LAGEOS satellites. Adv Space Res 63(1):6372. https://doi.org/10.1016/J.ASR.2018.08.010

Hellerschmied A, McCallum L, McCallum J, Sun J, Böhm J, Cao J, Hellerschmied A, McCallum L, McCallum J, Sun J, Böhm J, Cao J (2018) Observing APOD with the AuScope VLBI Array. Sensors 18(5):1587. https://doi.org/10.3390/s18051587

Kehm A, Bloßfeld M, Pavlis EC, Seitz F (2018) Future global SLR network evolution and its impact on the terrestrial reference frame. $\mathrm{J}$ Geod 92(6):625-635. https://doi.org/10.1007/s00190-017-10831

Kotsakis C (2018) Datum definition and minimal constraints. In: Grafarend E (ed) Encyclopedia of geodesy. Encyclopedia of earth sciences series. Springer, Cham. https://doi.org/10.1007/978-3319-02370-0

Lyard F, Lefevre F, Letellier T, Francis O (2006) Modelling the global ocean tides: modern insights from FES2004. Ocean Dyn 56(56):394-415. https://doi.org/10.1007/s10236-006-0086-x

Mendes VB, Pavlis EC (2004) High-accuracy zenith delay prediction at optical wavelengths. Geophys Res Lett 31(14):L14602. https:// doi.org/10.1029/2004GL020308

Noll CE, Ricklefs R, Horvath J, Mueller H, Schwatke C, Torrence M (2018) Information resources supporting scientific research for the international laser ranging service. J Geod. https://doi.org/10. 1007/s00190-018-1207-2
Otsubo T, Matsuo K, Aoyama Y, Yamamoto K, Hobiger T, Kubo-oka T, Sekido M (2016) Effective expansion of satellite laser ranging network to improve global geodetic parameters. Earth Planets Space 68(1):65. https://doi.org/10.1186/s40623-016-0447-8

Otsubo T, Mueller H, Pavlis EC, Torrence MH, Thaller D, Glotov V, Wang X, Sosnica K, Meyer U, Wilkinson M (2018) Rapid response quality control service for the laser ranging tracking network. J Geod. https://doi.org/10.1007/s00190-018-1197-0

Pavlis EC (1994) High resolution earth orientation parameters from LAGEOS SLR data analysis at GSFC in IERS Technical Note 16, 1994

Pavlis EC, Kuźmicz-Cieślak M (2016) SLR and the next generation global geodetic networks. In: Proceedings of 16th international workshop on laser ranging, Poznan, Poland

Pavlis NK, Holmes SA, Kenyon SC, Factor JK (2012) The development and evaluation of the Earth Gravitational Model 2008 (EGM2008). J Geophys Res Solid Earth. https://doi.org/10.1029/ 2011JB008916

Pearlman M, Degnan J, Bosworth J (2002) The International Laser Ranging Service. Adv Space Res 30(2):135-143. https://doi.org/ 10.1016/S0273-1177(02)00277-6

Pearlman M, Arnold D, Davis M, Barlier F, Biancale R, Vasiliev V, Ciufolini I, Paolozzi A, Pavlis E, Sośnica K, Blossfeld M (2019) Laser geodetic satellites: a high accuracy scientific tool. J Geod https://doi.org/10.1007/s00190-019-01228-y

Petit G, Luzum B (eds) (2010) IERS conventions 2010. IERS Technical Note 36. Verlag des Bundesamts für Kartographie und Geodäsie, Frankfurt am Main, Germany. http://iers-conventions.obspm.fr

Plag HP, Pearlman M (2009) The global geodetic observing system: meeting the requirements of a global society on a changing planet in 2020. Springer, Berlin

Ray J, Rebischung P, Griffiths J (2017) IGS polar motion measurement accuracy. Geod Geodyn 8(6):413-420. https://doi.org/10.1016/J. GEOG.2017.01.008

Rebischung P, Garayt B (2013) Reference frames for applications in geosciences vol 138, pp 69-74. https://doi.org/10.1007/978-3642-32998-2

Sośnica K (2014) Determination of precise satellite orbits and geodetic parameters using satellite laser ranging. Astronomical Institute, University of Bern, Bern. https://doi.org/10.7892/boris.53968

Sośnica K, Thaller D, Dach R, Jäggi A, Beutler G (2013) Impact of loading displacements on SLR-derived parameters and on the consistency between GNSS and SLR results. J Geod 87(8):751-769. https://doi.org/10.1007/s00190-013-0644-1

Sośnica K, Jäggi A, Thaller D, Beutler G, Dach R (2014) Contribution of Starlette, Stella, and AJISAI to the SLR-derived global reference frame. J Geod 88(8):789-804. https://doi.org/10.1007/ s00190-014-0722-z

Sośnica K, Jäggi A, Meyer U, Thaller D, Beutler G, Arnold D, Dach R (2015) Time variable Earth's gravity field from SLR satellites. J Geod 89(10):945-960. https://doi.org/10.1007/s00190015-0825-1

Sośnica K, Bury G, Zajdel R (2018) Contribution of Multi-GNSS constellation to SLR-derived terrestrial reference frame. Geophys Res Lett 45(5):2339-2348. https://doi.org/10.1002/2017GL076850

Sośnica K, Bury G, Zajdel R, Strugarek D, Drożdżewski M, Kazmierski K (2019) Estimating global geodetic parameters using SLR observations to Galileo, GLONASS, Beidou, GPS and QZSS. Earth Planets Space 71:20. https://doi.org/10.1186/s40623-019-1000-3

Strugarek D, Sośnica K, Arnold D, Jäggi A, Zajdel R, Bury G, Drożdżewski M (2019) Determination of global geodetic parameters using satellite laser ranging measurements to sentinel-3 satellites. Remote Sens 11(19):2282. https://doi.org/10. 3390/rs11192282

Thaller D, Sośnica K, Dach R, Jäggi A, Beutler G (2010) LAGEOSETALON solutions using the Bernese Software. Mitteilungen des 
Bundesamtes fuer Kartographie und Geodaesie. In: Proceedings of the 17th international workshop on laser ranging, extending the range, vol 48. Bad Kötzting, Frankfurt, pp 333-336

Thaller D, Dach R, Seitz M, Beutler G, Mareyen M, Richter B (2011) Combination of GNSS and SLR observations using satellite colocations. J Geod 85(5):257-272. https://doi.org/10.1007/s00190010-0433-Z

Weiss JP, Steigenberger P, Springer T (2017) Orbit and clock product generation. In: Teunissen PJ, Montenbruck O (eds) Springer handbook of global navigation satellite systems. Springer handbooks. Springer, Cham, pp 983-1010. https://doi.org/10.1007/ 978-3-319-42928-1_34

Wilkinson M, Schreiber U, Procházka I, Moore C, Degnan J, Kirchner G, Zhongping Z, Dunn P, Shargorodskiy V, Sadovnikov M, Courde C, Kunimori H (2018) The next generation of satellite laser ranging systems. J Geod. https://doi.org/10.1007/s00190-018-1196-1
Wu X, Ray J, van Dam T (2012) Geocenter motion and its geodetic and geophysical implications. J Geodyn 58:44-61. https://doi.org/10. 1016/j.jog.2012.01.007

Zajdel R, Sośnica K, Bury G (2017) A new online service for the validation of Multi-GNSS orbits using SLR. Remote Sens 9(10):1049. https://doi.org/10.3390/rs9101049

Zajdel R, Sośnica K, Dach R, Bury G, Prange L, Jäggi A (2019) Network effects and handling of the geocenter motion in multi-GNSS processing. J Geophys Res Solid Earth 124:5970-5989. https:// doi.org/10.1029/2019JB017443

Zelensky NP, Lemoine FG, Chinn DS, Melachroinos S, Beckley BD, Beall JW, Bordyugov O (2014) Estimated SLR station position and network frame sensitivity to time-varying gravity. J Geod 88(6):517-537. https://doi.org/10.1007/s00190-014-0701-4 